\title{
A Robust Adaptive Overcurrent Relay Coordination Scheme for Wind-Farm-Integrated Power Systems Based on Forecasting the Wind Dynamics for Smart Energy Systems
}

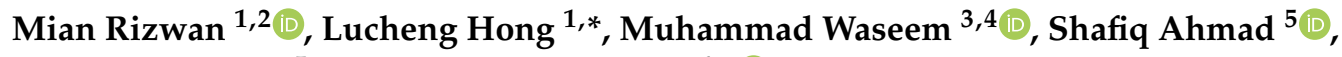 \\ Mohamed Sharaf ${ }^{5}$ and Muhammad Shafiq ${ }^{6, *(D)}$ \\ 1 Jiangsu Provincial Key Laboratory of Smart Grid Technology and Equipment, Southeast University, \\ Nanjing 210000, China; rizwan.nazeer26@uog.edu.pk \\ 2 Department of Electrical Engineering, University of Gujrat, Gujrat 50700, Pakistan \\ 3 Department of Electrical Engineering, Zhejiang University, Hangzhou 310027, China; mwaseem@zju.edu.cn \\ 4 Department of Electrical Engineering, University of Engineering and Technology, Taxila 47080, Pakistan \\ 5 Department of Industrial Engineering, College of Engineering, King Saud University, \\ Riyadh 11421, Saudi Arabia; ashafiq@ksu.edu.sa (S.A.); mfsharaf@ksu.edu.sa (M.S.) \\ 6 Department of Information and Communication Engineering, Yeungnam University, \\ Gyeongsan 38541, Korea \\ * Correspondence: hlc3061@seu.edu.cn (L.H.); shafiq@ynu.ac.kr (M.S.)
}

Received: 17 August 2020; Accepted: 8 September 2020; Published: 10 September 2020

\begin{abstract}
Conventional protection schemes in the distribution system are liable to suffer from high penetration of renewable energy source-based distributed generation (RES-DG). The characteristics of RES-DG, such as wind turbine generators (WTGs), are stochastic due to the intermittent behavior of wind dynamics (WD). It can fluctuate the fault current level, which in turn creates the overcurrent relay coordination (ORC) problem. In this paper, the effects of WD such as wind speed and direction on the short-circuit current contribution from a WTG is investigated, and a robust adaptive overcurrent relay coordination scheme is proposed by forecasting the $\mathrm{WD}$. The seasonal autoregression integrated moving average (SARIMA) and artificial neuro-fuzzy inference system (ANFIS) are implemented for forecasting periodic and nonperiodic WD, respectively, and the fault current level is calculated in advance. Furthermore, the ORC problem is optimized using hybrid Harris hawks optimization and linear programming (HHO-LP) to minimize the operating times of relays. The proposed algorithm is tested on the modified IEEE-8 bus system with wind farms, and the overcurrent relay (OCR) miscoordination caused by WD is eliminated. To further prove the effectiveness of the algorithm, it is also tested in a typical wind-farm-integrated substation. Compared to conventional protection schemes, the results of the proposed scheme were found to be promising in fault isolation with a remarkable reduction in the total operation time of relays and zero miscoordination.
\end{abstract}

Keywords: protection coordination; wind dynamics; wind-speed forecasting; seasonal autoregression integrated moving average (SARIMA); adaptive neural network-based fuzzy inference system (ANFIS); smart energy systems; system stability

\section{Introduction}

The integration of renewable energy source-based distributed generation (RES-DG), such as wind turbine generators (WTGs), in power systems is continuously increasing due to extensive technical developments, as well as clean and low-cost energy production [1,2]. The wind power share of 
worldwide electricity at the end of 2018 was $4.8 \%$, which could increase to $19 \%$ after ten years, thereby avoiding more than three billion tons of $\mathrm{CO}_{2}$ a year [3,4]. Aside from the benefits, RES-DGs change the radial distribution network (DN) into a meshed network and cause bidirectional power flow, which changes the fault current level (FCL) [5], resulting in conventional protection systems facing new challenges, most notably the overcurrent relay coordination (ORC) problem [6-9]. Overcurrent relay (OCR) measures the FCL and sends a trip signal after a typical operating time. The faulty portion is isolated from the healthy system if proper coordination is sustained between the primary and backup OCRs [10]. This relay coordination is maintained by delaying the upstream relays with a suitable time called the coordination time interval (CTI). Optimal relay settings, such as the pickup current (Ip) and time multiplier setting (TMS), play a vital role in achieving optimum ORC. These relay settings are fixed at predefined FCL and connected load [11,12]. The integration of wind farms (WF) into distribution systems is intermittent, depending on the operating conditions of the WTG, which mainly depend on the stochastic behavior of wind speed and direction. This results in changes in the FCL with WD, which affect the relay setting, thereby causing miscoordination problems $[13,14]$. Thus, the relay settings should be adaptively updated in line with the operating conditions of the WTG. To determine optimal relay settings, two approaches are used: conventional approaches (CA) [15-21] and optimization approaches (OA) [22-40].

Conventional approaches involve the predetermination and analysis of fault currents during abnormal conditions and system contingencies [15], which are dependent on the network configuration; they include curve-fitting techniques [16] computer programming software [17], graphical selection [18], minimum breakpoint set [19], and linear graph theory [20]. In a complex meshed network with multiple RES-DG, conventional methods are not suitable, as the time to update the relay settings during contingencies is prolonged and ORC becomes impracticable [21]. Thus, authors strived to propose optimization approaches. The overall purpose of optimization approaches in the ORC problem is to obtain the minimum possible operation time by optimally adjusting the OR settings subjected to constraints. Firstly, the ORC problem is formulated as linear programming (LP), in which one variable from $\mathrm{I}_{\mathrm{p}}$ and TMS is predetermined and the second is optimized [22,23]. In complex networks, the results of LP may be trapped in local minima. Hence, the ORC problem is formulated as nonlinear programming (NLP), where both settings of the relay are optimized at the same time, which is often formulated with metaheuristic techniques such as particle swarm optimization (PSO) [25], seeker optimization algorithm (SOA) [26], genetic algorithm (GA) [27], evolutionary optimization algorithm (EOA) [28], teaching learning-based algorithm (TLBO) [29], ant colony optimization (ACO), gravitational search algorithm (GSA) [30], symbiotic organism search optimization technique (SOSO) [31], and extended continuous domain ant colony optimization [32]. Some hybrid optimization approaches (HOAs) were also proposed in the literature by combining the benefits of different OAs. It is seen that HOAs produce good results in the form of less computational time, better accuracy, and reliability toward global optimization $[33,34]$. Some examples are the hybrid electro-search algorithm and cuckoo optimization (HES-CO) [35], hybrid PSO-LP [36], combined genetic algorithm and simulated annealing (GA-SA) [37], hybrid biogeography-based optimization and differential evolution (BBO-DE) [38], hybrid CS-GA [5], and hybrid CS-LP [39].

\section{Contributions and Paper Organization}

Subsequent to the variation in FCL from WTGs due to the stochastic nature of wind speed, wind direction, and metrological conditions in wind farm-dominated distribution networks, the relay settings can be disturbed. Therefore, the relay settings must be updated adaptively in line with the variation in FCL. In this paper, a robust adaptive overcurrent relay coordination scheme for a WTG-integrated distributed system based on forecasting WD is presented to deal with the variation in FCL. It forecasts the wind speed and direction and calculates the FCL in advance. Furthermore, the seasonal autoregression integrated moving average (SARIMA) and adaptive neural network-based fuzzy inference system (ANFIS) are adopted for forecasting the periodic and nonperiodic WD, respectively. On the basis of 
the predicted FCL, the ORC problem is formulated as an NLP problem and is tackled by hybrid Harris hawks optimization and linear programming (HHO-LP). The main purpose of employing HH-LP is to achieve a remarkable reduction in the total operating time of relays by optimizing the relay settings to reduce the level of equipment damage and nuisance-related WTG disconnection, and to improve the reliability.

The key contributions of this paper are as follows:

- The delay in updating the relay settings and the coordination with other relays can cause the malfunctioning of OCRs. A considerable delay time is evaded when updating the relay settings by predicting the wind speed and FCL variation in advance.

- $\quad$ The hybrid ANFIS-SARIMA is devised for predicting periodic and nonperiodic wind series.

- An efficient optimization model HHO-LP is established for the existing constraints.

- A significant reduction in the overall tripping time of relays is achieved.

- The is no record of miscoordination or limit violation.

The rest of the paper is organized as follows: Section 2 describes the problem formulation and objective functions for relay coordination. Section 3 addresses the proposed methodology. The investigated test systems and the obtained results are reflected in Section 4. Finally, Section 5 concludes the manuscript.

\section{Problem Formulation}

\subsection{Objective Function}

The fault current in a WTG WF varies with the variation in wind speed. This variation can adversely affect the ORC. Thus, the FCL needs to be determined in advance by forecasting the WD, which is coupled with an optimization algorithm (OA) for the overcurrent relay coordination problem. The OA reduces the total operation time of relays. The operation time of backup protection is of vital importance in protection coordination; thus, the time of operation for primary and backup relays is concurrently minimized.

$$
\mathrm{OF}=\operatorname{Min} \mathrm{F}_{\mathrm{OT}}=\sum_{\mathrm{f}=1}^{\mathrm{F}}\left[\sum_{\mathrm{i}=1}^{\mathrm{I}}\left[\mathrm{t}_{\mathrm{if}}^{\mathrm{p}}+\sum_{\mathrm{j}=1}^{\mathrm{J}} \mathrm{t}_{\mathrm{ijf}}^{\mathrm{b}}\right]\right],
$$

where $\mathrm{F}_{\mathrm{OT}}$ is the overall operation time of relays for fault isolation, $\mathrm{t}_{\mathrm{if}}^{\mathrm{p}}$ and $\mathrm{t}_{\mathrm{ijf}}^{\mathrm{b}}$ represent the operation time of the i-th primary relay and j-th backup relay, respectively, for a fault at location $\mathrm{f}$, and $\mathrm{F}, \mathrm{I}$, and J denote the set of fault points, the total primary relays, and the backup relays, respectively.

Normally, the OCR follows inverse time characteristics as follows:

$$
\mathrm{t}=\mathrm{TMS}\left[\frac{\mathrm{A}}{\left(\frac{\mathrm{I}}{\mathrm{I}_{\mathrm{P}}}\right)^{\mathrm{B}}-1}+\mathrm{C}\right]
$$

where $t$ is the operation time of the relay, I is the fault current, A denotes the constant for relay TCCs, and $\mathrm{B}$ denotes the inverse time type. As standard definitions are considered in Equation (2), A, B, and $\mathrm{C}$ are assumed constant. The terms $t_{\mathrm{if}}^{\mathrm{p}}$ and $\mathrm{t}_{\mathrm{ijf}}^{\mathrm{b}}$ can be expressed from Equation (2) as follows:

$$
\mathrm{t}_{\mathrm{if}}^{\mathrm{p}}=\mathrm{TMS}_{\mathrm{i}}^{\mathrm{p}}\left[\frac{\mathrm{A}}{\left(\frac{\mathrm{I}_{\mathrm{if}}}{\mathrm{I}_{\mathrm{i}}}\right)^{\mathrm{B}}-1}+\mathrm{C}\right],
$$




$$
\mathrm{t}_{\mathrm{ijf}}^{\mathrm{b}}=\mathrm{TMS}_{\mathrm{j}}^{\mathrm{b}}\left[\frac{\mathrm{A}}{\left(\frac{\mathrm{I}_{\mathrm{ijf}}}{\mathrm{I}_{\mathrm{pj}}}\right)^{\mathrm{B}}-1}+\mathrm{C}\right] .
$$

$\mathrm{TMS}_{\mathrm{i}}^{\mathrm{p}}$ and $\mathrm{TMS}_{j}^{\mathrm{b}}$ are the time multiplier settings of the i-th primary relay and $\mathrm{j}$-th backup relay, respectively. Similarly, $I_{P} i$ and $I_{P} j$ are the pickup currents of the primary and backup relays.

\subsection{OCR Coordination Constraints}

There should be enough time difference between the operating times of primary and backup relays, termed the coordination time interval (CTI), for the security of protection coordination.

$$
\Delta \mathrm{t}_{\mathrm{ij}}^{\mathrm{p}, \mathrm{b}}=\mathrm{t}_{\mathrm{i}}^{\mathrm{p}}-\mathrm{t}_{\mathrm{j}}^{\mathrm{b}}-\mathrm{CTI} \geq 0 ; \mathrm{i} \in \mathrm{I}, \mathrm{j} \in \mathrm{J} .
$$

The optimization variables TMS and $\mathrm{I}_{\mathrm{p}}$ are assessed within the lower and upper bounds given as

$$
\begin{gathered}
\mathrm{TMS}_{\mathrm{I}}^{\min } \leq \mathrm{TMS}_{\mathrm{i}} \leq \mathrm{TMS}_{\mathrm{i}}^{\max }, \\
\mathrm{I}_{\mathrm{p}, \mathrm{i}}^{\min } \leq \mathrm{I}_{\mathrm{p}, \mathrm{i}} \leq \mathrm{I}_{\mathrm{p}, \mathrm{i}}^{\max } .
\end{gathered}
$$

The value of $\mathrm{I}_{\mathrm{p}}$ should be more than the maximum load current and less than the minimum short-circuit current value. During temporary faults, the relays should not operate and, therefore, there is a minimum limit for the operation time of relays.

$$
t_{i} \geq t_{i}^{\min }
$$

\section{Proposed Methodology}

\subsection{EEMD}

Empirical mode decomposition (EMD) is effective in extracting the characteristic information from an original wind speed series, which can be decomposed into a set of intrinsic mode functions (IMFs). The IMFs indicate the oscillatory mode of the original wind speed series. EMD is a self-adaptive time series processing method, which can be perfectly used for complicated processing [40]. The main drawback of EMD is its mode mixing problem. To resolve the mode mixing problem, the EEMD method was proposed in [41]. The procedure of EEMD is described as follows:

(1) Initialize the number of ensembles (M) and the amplitude of the added white noise; set $i=1$.

(2) Add a white noise series to the original wind speed series $x(t)$.

$$
x_{i}(t)=x(t)+n_{i}(t)
$$

where $n_{i}(t)$ denotes the $i$-th added white noise series, and $x_{i}(t)$ denotes the series with the added white noise.

(3) Decompose the series $x i(t)$ into J IMFs $c i j(t)(j=1,2, \ldots, \mathrm{J})$ using the EMD method, where $\operatorname{cij}(t)$ is the $j$-th IMF after the $i$-th trial, and $\mathrm{J}$ is the number of IMFs.

(4) If $i<\mathrm{M}$, then go to Step (2) with $i=i+1$. Repeat Steps (2) and (3) with different white noise series.

(5) Calculate the ensemble mean $c j(t)$ of the $M$ trials for each IMF of the decomposition as the final results.

$$
c_{j}(t)=\frac{1}{M} \sum_{i=1}^{M} c_{i j}(t), i=1,2, \ldots \ldots, M, j=1,2, \ldots \ldots j .,
$$

where $c_{j}(t),(j=1,2, \ldots, \mathrm{J})$ is the $j$-th IMF component using the EEMD method. 


\subsection{ANFIS}

ANFIS is a multilayer feed forward network, which integrates the merits of neural networks and fuzzy inference systems [31]. In this paper, ANFIS with type-3 reasoning mechanisms was applied. The typical ANFIS with type-3 reasoning mechanisms consists of five layers, which are shown in Figure 1, the detailed descriptions of which are given in [31]. The functions of each layer are given below.

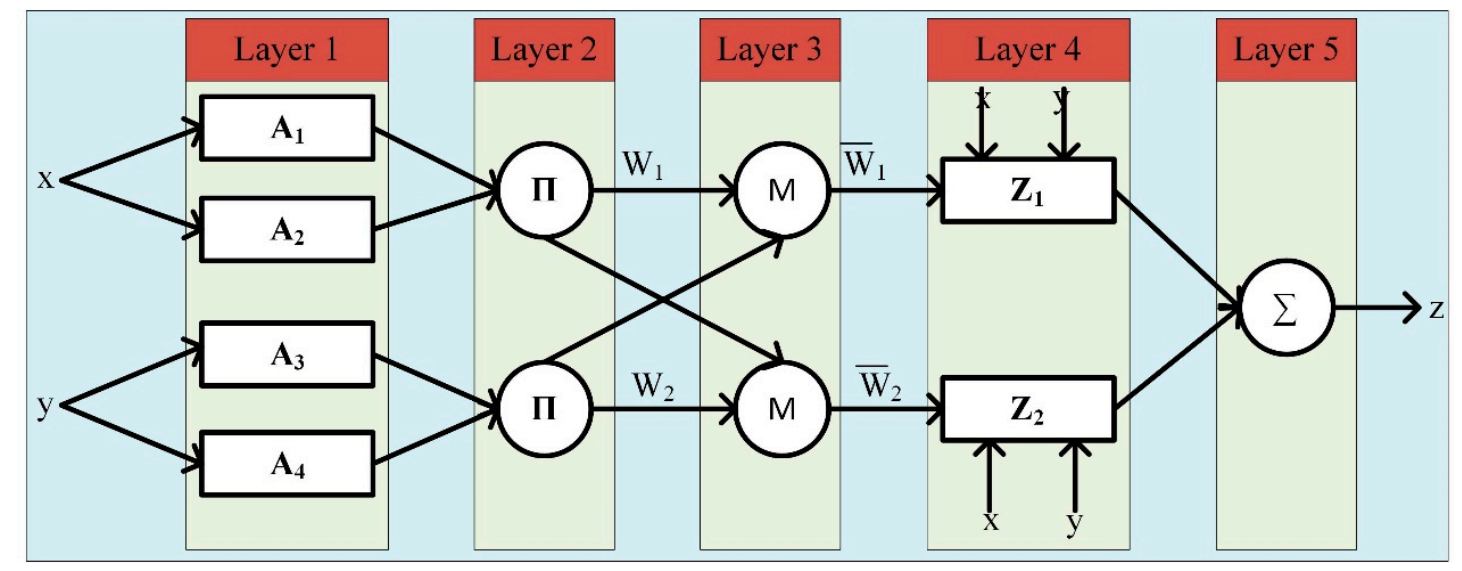

Figure 1. The architecture of the adaptive neural network-based fuzzy inference system (ANFIS) with type-3 reasoning mechanisms.

Layer 1: The outputs of this layer are defined as

$$
\begin{gathered}
O_{1, i}=\mu_{A i}(x), i=1,2, \\
O_{1, i}=\mu_{B i-2}(y), i=3,4,
\end{gathered}
$$

where $x$ or $y$ denotes the wind speed series, $O_{1, i}$ is the membership degree of fuzzy set $\left\{A_{1}, A_{2}\right\}$ or $\left\{\mathrm{B}_{1}, \mathrm{~B}_{2}\right\}$, and $\mu(x)$ or $\mu(y)$ is the membership function.

The following membership function is utilized:

$$
\mu_{A i}(x)=\exp \left[-0.5\left\{\left(x-c_{i}\right) / \sigma i\right\}\right] \quad \therefore i=1,2,
$$

where $\mu_{A i}(x)$ is the Gaussian function, and $c_{i}$ and $\sigma_{i}$ are the mean and standard deviation of the membership function, respectively.

Layer 2: This layer is the operation layer.

Layer 3: All the input variables are normalized in this layer, and the output of this layer is calculated as

$$
O_{3, i}=\bar{W}_{i}=\frac{W_{i}}{W_{1}+W_{2}} \quad \therefore i=1,2,
$$

where $O_{3, i}$ is the output of Layer 3 , and $W_{i}$ is the incentive strength of rule $i$.

Layer 4: The following node function is applied in this layer:

$$
z_{i}=\bar{W}_{i} f_{i}=\bar{W}_{i}\left(p_{i} x+q_{i} y+r_{i}\right) \quad \therefore i=1,2,
$$

where $\{p i, q i, r i\}$ is the parameter set of the nodes.

Layer 5: The single node in this layer summarizes all incoming series as follows:

$$
z=\bar{W}_{1} z_{1}+\bar{W}_{2} z_{2}
$$




\subsection{SARIMA}

SARIMA is the most popular method for periodic time series prediction, which is described as follows:

$$
F(B) U\left(B^{s}\right)(1-B)^{d}\left(1-B^{s}\right)^{D} Z_{t}=Q(B) V\left(B^{s}\right) e_{t},
$$

where $\mathrm{F}(\mathrm{B})$ and $\mathrm{U}\left(\mathrm{B}^{\mathrm{s}}\right)$ denote nonperiodic and periodic autoregressive polynomials, respectively, $\mathrm{Q}(\mathrm{B})$ and $\mathrm{V}\left(\mathrm{B}^{\mathrm{s}}\right)$ denote nonperiodic and periodic moving average polynomials, respectively, $\mathrm{Z}_{\mathrm{t}}$ denotes the wind speed series, et represents the white noise series, $d$ is the level of integration, $D$ is the level of periodic integration, $\mathrm{s}$ is the order of periodicity, and $\mathrm{B}$ is the back-shift operator. More details about SARIMA can been found in [42].

\subsection{Hybrid ANFIS-SARIMA Model}

A composite algorithm comprising ensemble empirical mode decomposition (EEMD), ANFIS, and SARIMA can be utilized for short-term wind speed forecasting $[43,44]$. Due to the stochastic nature of WD, deep insight into the actual wind speed series (WSS) is paramount to get accurate results. The original WSS contains periodic and nonperiodic series. Thus, a composite method with the capability of modeling periodic and nonperiodic series is an efficient choice for wind-speed forecasting. The EEMD decomposes the original WSS into a set of intrinsic mode functions (IMFs) of periodic and nonperiodic series. SARIMA forecasts the periodic WSS and ANFIS forecasts the nonperiodic WSS. The artificial neural network-based ANFIS-SARIMA constitutes better nonlinear ability, adaptivity, associative learning ability, and fault tolerance. To predict the WSS data of the $n$-th interval, the data of the $(n-1)$-th interval are also taken into account for better results. The inputs taken into account are local time, temperature, pressure, and humidity, whereas the outputs are wind direction, wind speed, and WT output power. The step-by-step procedure from WD forecasting to FCL calculation is described below.

(i) The WSS is decomposed into IMFs, and one residual series is given as

$$
\mathrm{S}(\mathrm{t})=\sum_{\mathrm{i}=1}^{\mathrm{n}} \mathrm{I}_{\mathrm{i}}(\mathrm{t})+\mathrm{R}_{\mathrm{n}}(\mathrm{t}),
$$

where $S(t)$ is the wind speed series, $I_{i}(t)$ represents the IMFs, and $R_{n}(t)$ is the residual series.

(ii) The periodic and nonperiodic series of $I_{i}(t)$ and $R_{n}(t)$ are defined as $P_{j}(t)$ and $N_{i}(t)$, respectively. Thus, the original wind speed series can be given as

$$
\mathrm{S}(\mathrm{t})=\sum_{\mathrm{i}=1}^{\mathrm{m}} \mathrm{N}_{i}(\mathrm{t})+\sum_{\mathrm{j}=\mathrm{m}+1}^{\mathrm{n}} \mathrm{P}_{\mathrm{j}}(\mathrm{t})+\mathrm{R}_{\mathrm{n}}(\mathrm{t}),
$$

where $N_{i}(t)$ is the nonperiodic WSS, and $P_{j}(t)$ is the periodic WSS.

(iii) For $P_{j}(t)$, the SARIMA model is implemented and the results are defined as $\hat{P}_{j}(t)$, Whereas, for $\mathrm{N}_{\mathrm{i}}(\mathrm{t})$ and $\mathrm{R}_{\mathrm{n}}(\mathrm{t})$, the ANFIS model is implemented and the results are defined as $\hat{\mathrm{N}}_{\mathrm{i}}(\mathrm{t})$ and $\hat{\mathrm{R}}_{n}(\mathrm{t})$. The sum of results of ANFIS-SARIMA is the forecasted wind speed given as

$$
\hat{S}(t)=\sum_{i=1}^{m} \hat{N}_{i}(t)+\sum_{j=m+1}^{n} \hat{P}_{j}(t)+\hat{R}_{n}(t) .
$$

(iv) On the basis of the predicted wind speed in Equation (20), the wind power can be expressed in the form of wind power flux or kinetic energy flux given as

$$
\mathrm{P}_{(\mathrm{WT})}=\frac{1}{2} \rho_{(\mathrm{t})} \mathrm{C}_{\mathrm{p}} \mathrm{AS}^{3}(\mathrm{t}),
$$




$$
\rho_{(\mathrm{t})}=\frac{\mathrm{P}_{(\mathrm{t})}}{\mathrm{R}_{\mathrm{s}} \times \mathrm{T}_{(\mathrm{t})}},
$$

where $\rho_{(t)}$ is the density of air, $P_{(t)}$ is the atmospheric pressure, $R_{s}$ is the specific gas density, and $T_{(t)}$ is the atmospheric temperature. A is the rotor swept area, $C_{p}$ is the coefficient of maximum power, and $S(t)$ is the forecasted wind speed. If the wind hits the turbine at an angle $\varphi_{(t)}$, as shown in Figure 2, then the azimuthal angle variation in the airflow can be considered as $\cos \varphi_{(\mathrm{t})}$, and Equation (21) can be written as

$$
\mathrm{P}_{(\mathrm{WT})}=\frac{1}{2} \rho_{(\mathrm{t})} \mathrm{C}_{\mathrm{p}} \mathrm{A}\left[\mathrm{S}(\mathrm{t}) \cos \varphi_{(\mathrm{t})}\right]^{3} .
$$

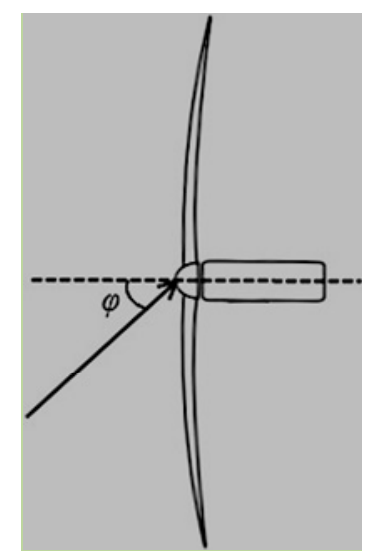

Figure 2. Wind hitting the rotor at an angle $\varphi$ in the horizontal plane.

Usually, the quantity of interest is the temporal average of the power. In order to derive an expression for the temporal average of the power, we use Reynold's decomposition [45].

$$
S_{(t)}=\bar{S}_{(t)}+s^{\prime}(t) \text { and } \varphi_{(t)}=\bar{\varphi}_{(t)}+\varphi^{\prime}(t) \prime
$$

where $\bar{S}_{(t)}$ and $\bar{\varphi}_{(t)}$ are the temporal means of the wind speed and wind direction, respectively, while $s^{\prime}(t)$ and $\varphi_{(t)}^{\prime}$ are perturbations or fluctuations about their respective means. Hereafter, for simplicity the notation $(t)$ is removed from all terms. Substituting Equation (24) into Equation (23) and performing Taylor's expansion and neglecting higher-order terms [46], we have

$$
\overline{\mathrm{P}}_{(\mathrm{WT})}=\frac{1}{2} \rho \mathrm{C}_{\mathrm{p}} \mathrm{A} \overline{\mathrm{S}}^{3}\left[1+3\left(\frac{\sigma_{\mathrm{u}}}{\overline{\mathrm{U}}}\right)^{2}\right]\left[1-\frac{\bar{\varphi}^{2}}{2}-\frac{\sigma_{\varphi}^{2}}{2}\right]^{3},
$$

where $\sigma_{u}^{2}$ is the variance of wind speed and $\sigma_{\varphi}^{2}$ is the variance of direction.

(v) The squirrel-cage induction generator (SCIG) and doubly fed induction generator (DFIG) are used almost exclusively in the energy conversion stage of the induction generator wind power system. In this study, SCIG was used. The most commonly used system topology is an SCIG directly connected to the power grid, as shown in Figure 3. This topology implies a constant frequency and voltage of the SCIG that establishes a fixed-speed operation. In such a system, the SCIG relies on the grid (or capacitor bank) to provide reactive power, which is necessary to build electromagnetic excitation for the rotary field. The generating mode of the SCIG is triggered by driven torque, which acts opposite to the generator speed within the super-synchronous speed operation region. Due to the absence of a power electronics interface, such a system can only serve the grid support applications, wherein just limited control (pitch-angle control) can be applied. 


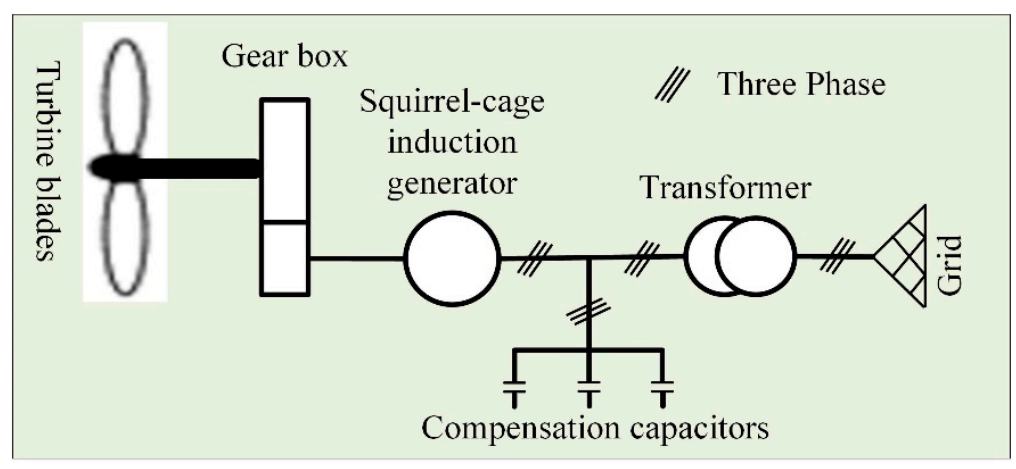

Figure 3. Fixed-speed wind turbine induction generator.

Now that the mechanical power of the rotor is known, it must be determined how much of this power is transferred to the electrical grid. A simplified overview of energy transfer from wind to the electrical grid is shown in Figure 4.

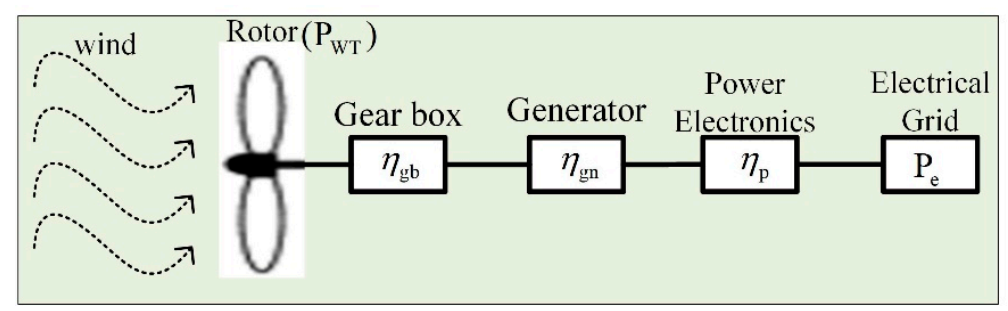

Figure 4. Energy transfer from wind to electrical grid.

(vi) The electrical power transferred to the grid is given as

$$
\mathrm{P}_{\mathrm{e}}=\eta_{\mathrm{gb}} \eta_{\mathrm{gn}} \eta_{\mathrm{p}}\left(\mathrm{P}_{\mathrm{WT}}\right)
$$

Here, the efficiency for the gearbox is 0.95 , that for the generator is 0.97 , and that for the power electronics device is 0.98 [47]. the current from the WTG in the wind farm can be calculated as

$$
\mathrm{I}_{\mathrm{WTG}}=\frac{\mathrm{P}_{\mathrm{e}}}{\sqrt{3} \times \cos \phi \times \mathrm{V}_{\mathrm{L}}},
$$

where $\cos \phi$ is the power factor, and $\mathrm{V}_{\mathrm{L}}$ is the line voltage.

(vii) The fault current from a three-phase fault in a squirrel-cage induction machine is calculated using the network shown in Figure 5 [48]. The short-circuit current value at $t=0$ is given as

$$
\begin{gathered}
I_{S C}=\frac{E^{\prime}}{R_{S}+j X^{\prime}} \\
E^{\prime}=V_{S}-\left(R_{L}+j X_{L}\right) I_{W T G}-\left(R_{s}+j X^{\prime}\right) I_{W T G} \\
X^{\prime}=X_{s}+\frac{X_{m} X_{r}}{X_{m}+X_{r}}
\end{gathered}
$$

where $E$ ' is the voltage behind transient reactance $X^{\prime}, R_{s}$ is the stator resistance, $X_{s}$ and $X_{r}$ are the leakage reactance of the stator and rotor, respectively, $X_{m}$ is the magnetizing reactance, and $R_{L}$ 
and $X_{\mathrm{L}}$ are the resistance and reactance of the line connecting the WTG and grid. Substituting Equation (29) into Equation (28), the short-circuit current for a particular instance can be given as

$$
I_{S C}=\frac{V_{s}-\left(R_{L}+j X_{L}\right) I_{W T G}}{R_{S}+j X^{\prime}} .
$$

All the terms in Equation (31) are constant for an SCIG; thus, the fault current depends upon the value of IWTG calculated in Equation (16), which depends upon the wind speed. The total fault current from a wind farm is the sum of fault currents from all the WTGs.

$$
\mathrm{I}_{\mathrm{SC}_{\text {Total }}}=\sum_{\mathrm{i}=1}^{\mathrm{n}} \mathrm{I}_{\mathrm{SC}}=\sum_{\mathrm{i}=1}^{\mathrm{n}}\left(\frac{\mathrm{E}^{\prime}}{\mathrm{R}_{\mathrm{S}}+\mathrm{j} \mathrm{X}^{\prime}}\right) \text {. }
$$

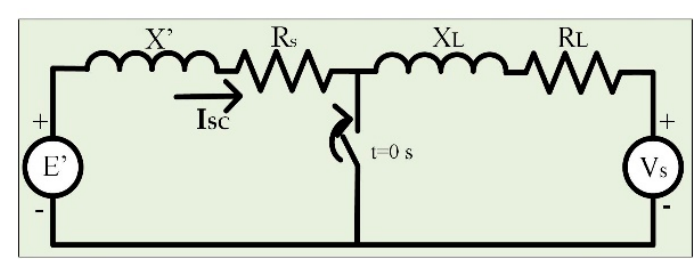

Figure 5. Sequence network circuit for three-phase fault.

\subsection{Hybrid HHO-LP Optimization Algorithm}

The simultaneous optimization of TMS and $\mathrm{I}_{\mathrm{p}}$ makes the ORC a nonlinear problem (NLP). A hybrid HHO-LP is proposed to solve this NLP by converting it into a linear programming (LP) problem. The basic technique involves the decomposition of the ORC problem into two subproblems. In the first subproblem, a random value is assigned to $I_{p}$ within its limits. This is only for the first iteration. Later on, its value is updated by the HHO. This converts the NLP into an LP. HHO calls the second subproblem in each iteration, which optimizes the TMS variable by using the standard LP method. This process continues until the convergence of the solution to an optimal value. Detailed descriptions of $\mathrm{HHO}$ and LP are given below.

\subsubsection{Harris Hawks Optimization}

HHO is a population-based algorithm proposed in [49], which mimics the hunting behavior of Harris hawks. It comprises exploration and exploitation. During the exploration phase, the position of hawks is updated on the basis of switches $(\varepsilon)$ in attacking tactics as follows:

$$
\begin{gathered}
P_{(t+1)}=P_{\text {best }(t)}-P_{a v g(t)}-r_{1}\left[L L+r_{2}(U L-L L)\right] \text { for } \varepsilon<0.5, \\
P_{(t+1)}=P_{\operatorname{rand}(t)}-r_{3}\left|P_{\operatorname{rand}(t)}-2 \times r_{4} \times P_{(t)}\right| \text { for } \varepsilon \geq 0.5,
\end{gathered}
$$

where $\mathrm{P}_{(\mathrm{t})}$ and $\mathrm{P}_{(\mathrm{t}+1)}$ are the position vectors of hawks at $\mathrm{t}$ and $\mathrm{t}+1$ iterations, respectively, $\mathrm{P}_{\operatorname{rand}(\mathrm{t})}$ is a randomly selected hawk position from the current population, $\mathrm{P}_{\mathrm{avg}(\mathrm{t})}$ is the average position of hawks, Pbest $(t)$ is the prey position, LL and UL are the lower and upper limits of the position variables, and $r_{1}$, $r_{2}, r_{3}$, and $r_{4}$ re random values selected from the range $[0,1]$.

The next stage is the transition from exploration to exploitation, which is executed by the change in different exploitative expressions, which depends on the escaping energy (E) of prey, as given in Equation (35).

$$
\mathrm{E}=2 \times \mathrm{E}_{0} \times\left(1-\frac{\mathrm{t}}{\mathrm{t}_{\max }}\right),
$$


where $t$ is the current iteration, $t_{\max }$ is the total number of iterations, and $E_{0}$ and $E$ are the initial and current escape energies of prey randomly selected taken from $[-1,1]$. During the attack of hawks in the exploitation phase, the prey has ( $\mathrm{r}$ ) probability of escaping. On the basis of the escape energy and the escape probability of prey, the hawks can espouse one of the four strategies tabulated in Table 1.

Table 1. Hunting strategies of Harris hawks during exploitation phase.

\begin{tabular}{cccc}
\hline No & Strategies & Escape Energy (E) & Escape Probability (r) \\
\hline 1 & Soft siege (SS) & $\mathrm{E} \geq 0.5$ & $\mathrm{r} \geq 0.5$ \\
2 & Soft siege with progressive rapid dives (SSPRD) & $\mathrm{E} \geq 0.5$ & $\mathrm{r}<0.5$ \\
3 & Hard siege (HS) & $\mathrm{E}<0.5$ & $\mathrm{r} \geq 0.5$ \\
4 & Hard siege with progressive rapid dives (HSPRD) & $\mathrm{E}<0.5$ & $\mathrm{r}<0.5$ \\
\hline
\end{tabular}

The positions of hawks are updated during SS and SSPRD using Equations (36) and (37), respectively.

$$
\begin{gathered}
\mathrm{P}_{(\mathrm{t}+1)}=\Delta \mathrm{P}_{(\mathrm{t})}-\mathrm{E}\left|\mathrm{J} \times \mathrm{P}_{\text {best }(\mathrm{t})}-\mathrm{P}_{(\mathrm{t})}\right|, \\
\therefore \Delta \mathrm{P}_{(\mathrm{t})}=\mathrm{P}_{\text {best }(\mathrm{t})}-\mathrm{P}_{(\mathrm{t})}, \mathrm{J}=2\left(1-\mathrm{r}_{5}\right) \\
\mathrm{P}_{(\mathrm{t}+1)}=\left\{\begin{array}{l}
\mathrm{C} \text { if Fit }(\mathrm{c})<\mathrm{P}_{(\mathrm{t})} \\
\mathrm{R} \text { if Fit }(\mathrm{R})<\mathrm{P}_{(\mathrm{t})}
\end{array}\right. \\
\therefore \mathrm{C}=\mathrm{P}_{\text {best }(\mathrm{t})}-\mathrm{E} \mid \mathrm{J} \times \mathrm{P}_{\text {best }(\mathrm{t})}-\mathrm{P}_{(\mathrm{t})}, \mathrm{R}=\mathrm{C}+\mathrm{S} \times \mathrm{LF}(\mathrm{D}),
\end{gathered}
$$

where $\mathrm{J}$ is the random escape power of prey, $\Delta \mathrm{P}_{(\mathrm{t})}$ is the difference between the position vectors of the prey and hawk, and $r_{5}$ is a randomly selected number within the range $[0,1]$.

The positions of hawks are updated during HS and HSPRD using Equations (38) and (39), respectively.

$$
\begin{gathered}
\mathrm{P}_{(\mathrm{t}+1)}=\mathrm{P}_{\text {best }(\mathrm{t})}-\mathrm{E}\left|\Delta \mathrm{P}_{(\mathrm{t})}\right|, \\
\mathrm{P}_{(\mathrm{t}+1)}=\left\{\begin{array}{l}
\mathrm{C} \text { if Fit }(\mathrm{c})<\mathrm{P}_{(\mathrm{t})}, \\
\mathrm{R} \text { if Fit }(\mathrm{R})<\mathrm{P}_{(\mathrm{t})}
\end{array}\right. \\
\therefore \mathrm{C}=\mathrm{P}_{\text {best }(\mathrm{t})}-\mathrm{E}\left|\mathrm{J} \times \mathrm{P}_{\text {best }(\mathrm{t})}-\mathrm{P}_{\mathrm{m}(\mathrm{t})}\right|, \mathrm{P}_{\mathrm{m}(\mathrm{t})}=\frac{1}{\mathrm{~N}} \sum_{\mathrm{j}=1}^{\mathrm{N}} \mathrm{X}_{\mathrm{i}(\mathrm{t})},
\end{gathered}
$$

where $C$ and $R$ are the values of current movements and rapid dives, $L F$ is levy flight, and $P_{m(t)}$ is the average position of hawks.

\subsubsection{Linear Programming}

To convert the NLP into a linear one, the value of $\mathrm{I}_{\mathrm{p}}$ is fixed as extracted from HHO. The linear programming subproblem is called repeatedly by HHO to compute the value of TMS and the fitness of each hawk corresponding to the $\mathrm{I}_{\mathrm{p}}$. A penalty relative to the severity of violation is added to the fitness value of each hawk if it violates the inequality coordination constraint. The complete algorithm of the proposed methodology for forecasting wind coupled with HHO-LP optimization algorithm is shown in Figure 6. In this study, short-term wind forecasting is used. The predicted wind speed, wind direction, and metrological variables are compared with the actual ones, and the predicted data are modified if the error exceeds the limits. On the basis of the predicted wind dynamics, the fault current is calculated in advance, and HHO-LP optimizes the ORC problem. The algorithm continuously checks if there is any change in wind data during a specified time interval; then, the fault current is calculated accordingly, and the relay settings are updated. The total time from forecasting to the upgrading of relay settings is given as

$$
\Delta \mathrm{T}=\Delta \mathrm{T}_{\mathrm{F}}+\Delta \mathrm{T}_{\mathrm{HHO}-\mathrm{LP}}+\Delta \mathrm{T}_{\mathrm{t}}
$$


where $\Delta \mathrm{T}_{\mathrm{F}}$ is the time taken by ANFIS-SARIMA to calculate the predicted wind power and fault current, $\Delta \mathrm{T}_{\mathrm{HHO}} \mathrm{LP}$ is the time consumed by HHO-LP to compute the optimum values of relay variables, and $\Delta \mathrm{T}_{\mathrm{t}}$ is the time required to transfer the values of $\mathrm{I}_{\mathrm{p}}$ and TMS to the relay.

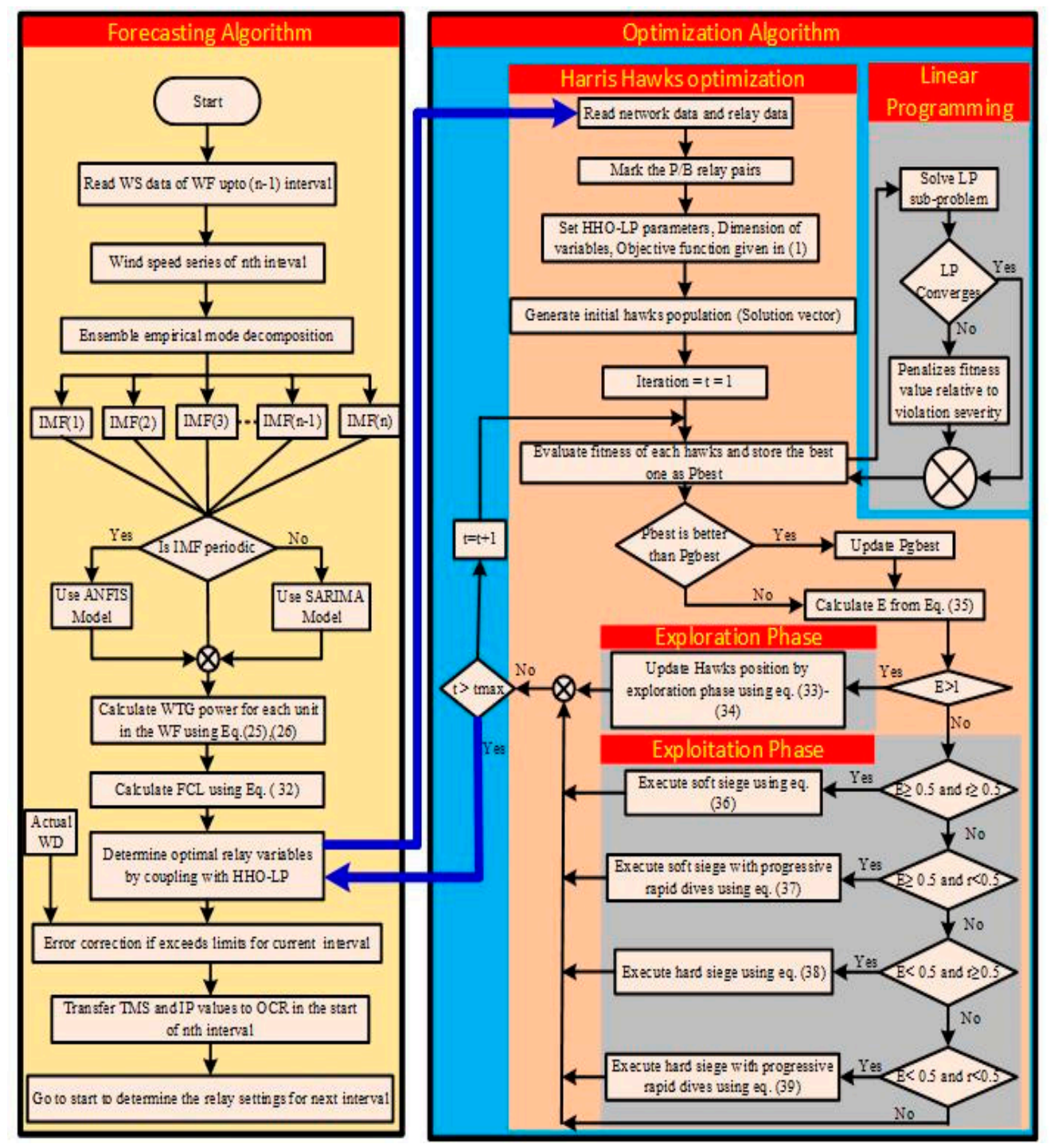

Figure 6. The hybrid ANFIS-seasonal autoregression integrated moving average (SARIMA) forecasting algorithm coupled with the hybrid Harris hawks optimization and linear programming (HHO-LP) optimization algorithm.

\section{Case Studies}

The impact of wind speed, wind direction, and metrological conditions on the variation in FCL in a wind-farm-integrated power system was observed by using the wind-speed prediction model, i.e., hybrid ANFIS-SARIMA. To increase the reliability of the power system, relay settings are updated continuously according to the predicted variation in FCL caused by wind speed. HHO-LP is incorporated to find the optimal values of TMS and $\mathrm{I}_{\mathrm{p}}$ for a minimization of the total operation time of primary and backup relays for the fastest fault isolation.

The short-term interval ( $5 \mathrm{~min}$ ) wind-speed data for the year 2019 collected from the southern parts of Pakistan, Jamshoro city, Sindh province, were used to train the ANFIS-SARIMA model. The latitude and longitude of this geographical location are 25.4007 and 68.2662 , respectively. The predicted and actual wind speed, wind direction, and metrological conditions for one day in all four seasons are 
shown in Figures 7-9, respectively. It can be observed that the prediction of wind direction is harder than that of wind speed, as it requires extensive computation time.
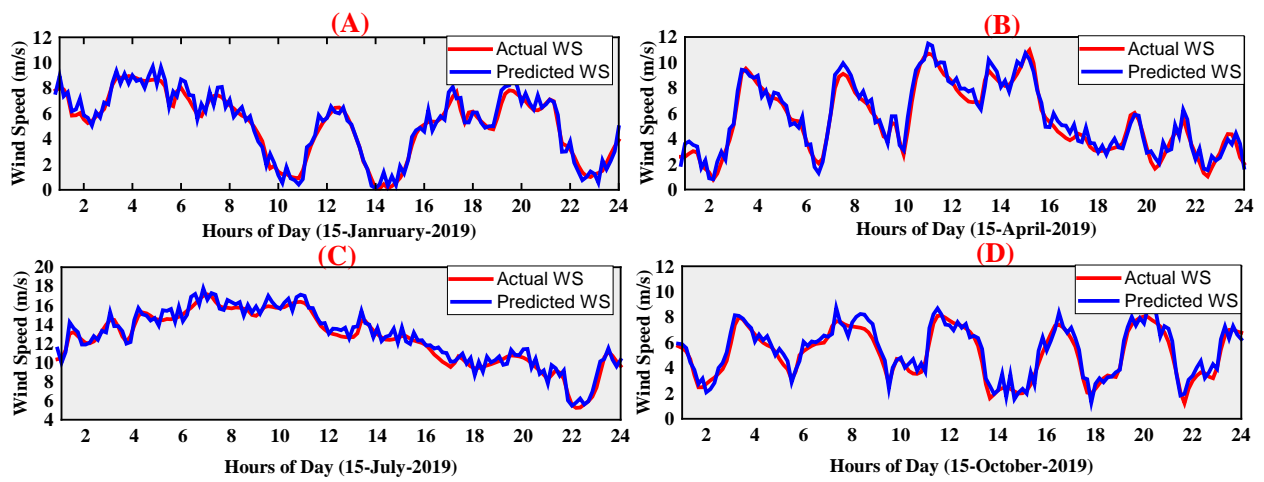

Figure 7. Variation in wind speed for one day during (A) winter, (B) summer, (C) spring, and (D) autumn.
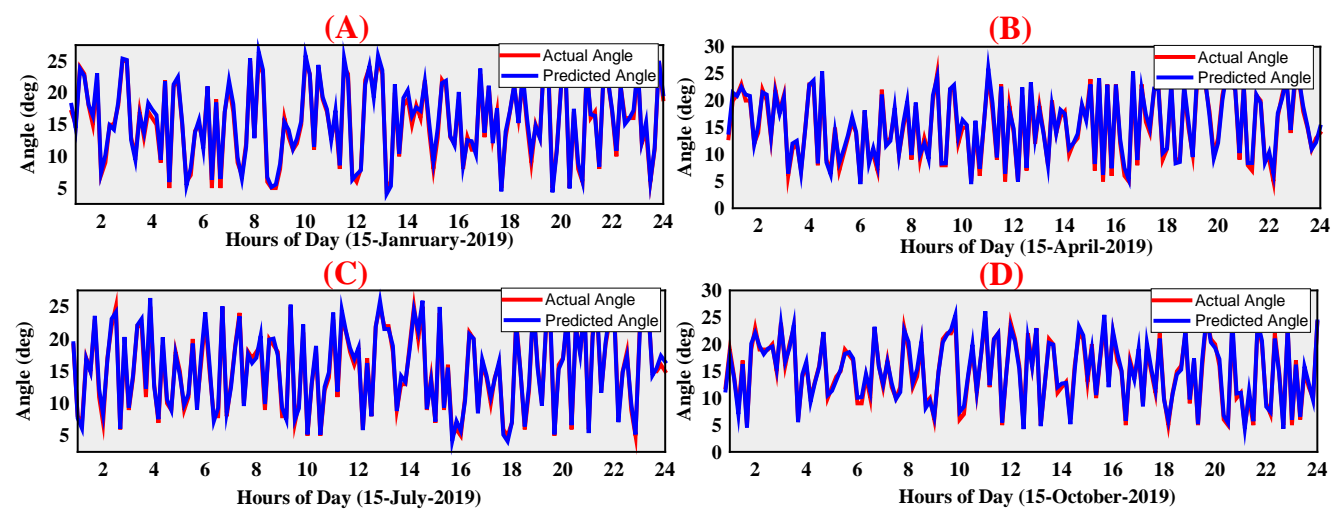

Figure 8. Variation in the angle of attack for one day during (A) winter, (B) summer, (C) spring, and (D) autumn.

(A)
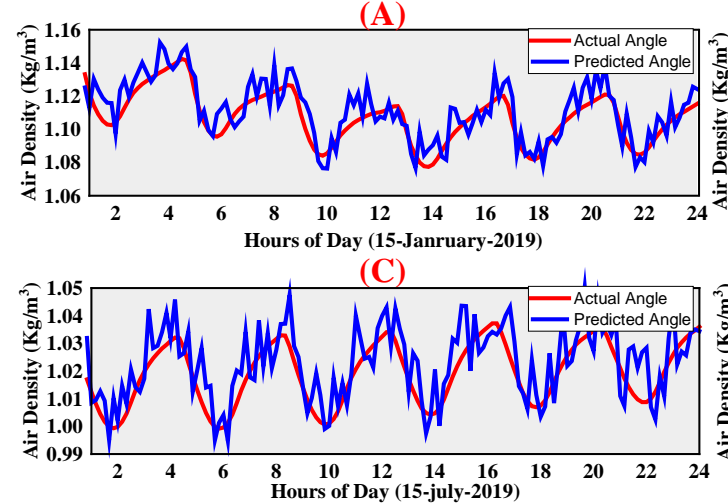

(B)

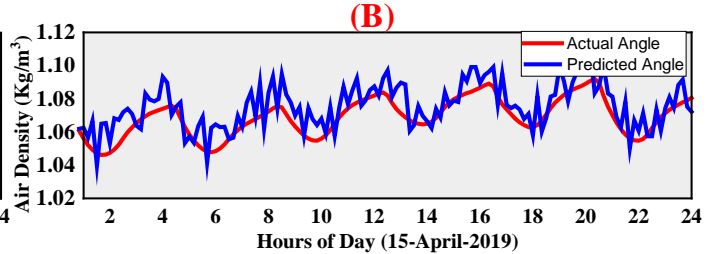

(D)

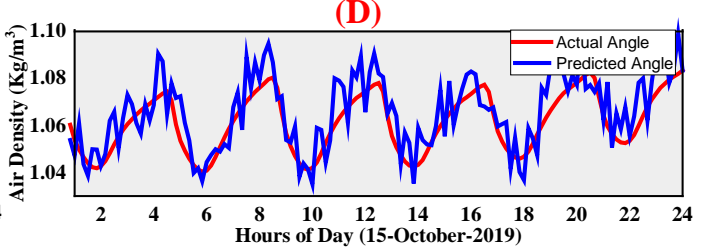

Figure 9. Variation in air density for one day during (A) winter, (B) summer, (C) spring, and (D) autumn.

It can be seen that the wind speed is highest during the spring season, resulting in a maximum chance of disturbing the protection coordination. The efficiency of the hybrid ANFIS-SARIMA model in terms of error compared with the state-of-the-art techniques reported in the literature such as fine tuning support vector machines(FTSVM) [50], modified persistence model(MPM) [51], convolutional neural network-radial basis function neural network(CNN-RBFNN) [52] and stacked extreme learning machine(SELM) [53] is reflected in Table 2. 
Table 2. Error comparison with state-of-the-art methods for the spring season.

\begin{tabular}{cccccc}
\hline Errors & FTSVM [50] & MPM [51] & CNN-RBFNN [52] & SELM [53] & Hybrid ANFIS-SARIMA \\
\hline ME & 0.0947 & 0.0850 & 0.0764 & 0.0658 & 0.0625 \\
MAE & 1.3412 & 1.3210 & 1.3072 & 1.1064 & 0.9643 \\
MSE & 16.512 & 15.5413 & 13.7651 & 11.5614 & 11.0312 \\
RMSE & 3.2314 & 3.1150 & 2.8574 & 2.4358 & 2.3519 \\
ESD & 4.6864 & 4.5754 & 4.1523 & 3.9525 & 3.8798 \\
\hline
\end{tabular}

\subsection{Test System Specification}

The IEEE-8 bus system and a real wind-farm-integrated substation named the Jhimpir power substation in Jamshoro, Pakistan, were considered testbeds for an evaluation of the performance of the proposed approach.

The ANFIS-SARIMA model and HHO-LP optimization technique were implemented in a registered version of Matlab-2020(R2002a). The fault analysis was carried out on the Electrical Analysis Transient Program (ETAP) software. The operating system had a processor Intel(R) Core ${ }^{\mathrm{TM}}$ i5-4210 central processing unit (CPU) at $1.7 \mathrm{GHz}-2.4 \mathrm{GHz}$ with $4 \mathrm{~GB}$ of random-access memory (RAM).

\subsubsection{IEEE-8 Bus System}

The standard IEEE-8 bus system is a meshed distribution system with multiple sources [54]. It consists of eight buses and seven line segments. Three-phase faults were simulated at the midpoint of each line segment. There were a total of 14 directional overcurrent relays (DOCR). These relays comprised 20 primary-backup relay pairs, as given in Table 3. To study the effect of wind speed on FCL variation, two wind farms were integrated at bus-3 and bus-6. The details of WTGs in the wind farms are given in Appendix A Table A1. A one-line diagram of the IEEE- 8 bus system is given in Figure 10.

Table 3. Primary (PR) and backup (BR) relay pairs for the IEEE-8 bus system.

\begin{tabular}{cccccccccccc}
\hline Fault & Pair & PR & BR & Fault & Pair & PR & BR & Fault & Pair & PR & BR \\
\hline \multirow{3}{*}{ F1 } & 1 & 1 & 6 & \multirow{2}{*}{ F3 } & 7 & 3 & 2 & & 14 & 6 & 5 \\
& 2 & 8 & 7 & & 8 & 10 & 11 & F6 & 15 & 6 & 14 \\
& 3 & 8 & 9 & \multirow{2}{*}{ F4 } & 9 & 4 & 3 & & 16 & 13 & 8 \\
& 4 & 2 & 1 & & 10 & 11 & 12 & & 17 & 7 & 5 \\
F2 & 5 & 2 & 7 & & 11 & 5 & 4 & F7 & 18 & 7 & 13 \\
& 6 & 9 & 10 & F5 & 12 & 12 & 13 & & 19 & 14 & 1 \\
& & & & & 13 & 12 & 14 & & 20 & 14 & 9 \\
\hline
\end{tabular}

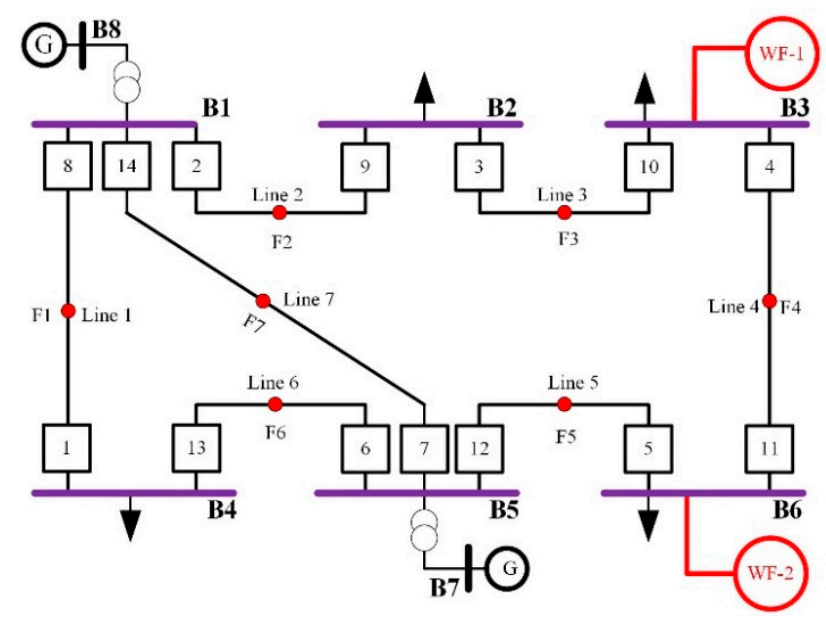

Figure 10. Standard IEEE-8 bus system modified by integrating wind turbine generators. 
GE Multilin750/760 numerical relays were employed here. The CT ratio for all relays was 400:1. The minimum and maximum limits of TMS were 0.05 and 1.1, respectively, whereas the limits for $\mathrm{I}_{\mathrm{p}}$ were $1.1 \times \mathrm{I}_{\text {Load }}$ and $1.5 \times \mathrm{I}_{\text {Load }}$. The CTI can take a value between 0.2 and 0.5 (REFF). However, for analysis of the IEEE- 8 bus system, it was taken as 0.3 . The minimum and maximum operation times of the relay were kept as 0.1 and 2.5 , respectively, to assure the reliability of the proposed protection scheme.

Two case studies were carried out. In the first case, the wind speed and wind direction were taken as $10 \mathrm{~m} / \mathrm{s}$ and $5^{\circ}$, respectively, whereas, in the second case, the wind speed was $20 \mathrm{~m} / \mathrm{s}$ and the wind direction was $10^{\circ}$. Figure 11 depicts the variation in FCL due to wind speed for all 20 relay pairs for both cases. It is reflected that the fault current increased as the wind speed increased, as described in Equation (16). If the conventional relay settings are not updated according to wind-speed variation after WTG integration, then the variation in FCL due to WS variation can cause miscoordination in primary-backup relay pairs. Thus, using the predicted FCL by ANFIS-SARIMA, the relay settings were optimally updated by hybrid HHO-LP. The relay settings for a wind speed of $10 \mathrm{~m} / \mathrm{s}$ obtained using conventional, PSO-LP [55], and HHO-LP methods are given in Table 4. Table 5 provides the time of operation of primary-backup relays for the first case. It can be seen that, in some cases, relay pairs violated the CTI limit. For example, in relay pair 6 in the first case, the backup relay R10 and primary relay $\mathrm{R} 9$ could not maintain a CTI of 0.3 , thereby disturbing the protection coordination. On the other hand, in relay pair 10, both primary and backup relays operated at the same time. Figure 12a shows the characteristic curve of relay pair 6 taken during the simulation in ETAP, with conventional relay settings during the first case. The relay settings were updated optimally by HHO-LP on the basis of the predicted fault current, and the relay characteristics for the same relay pair 6 with the updated relay settings are shown in Figure 12b. It can be seen that the CTI of 0.3 was maintained between primary and backup relays for this pair.

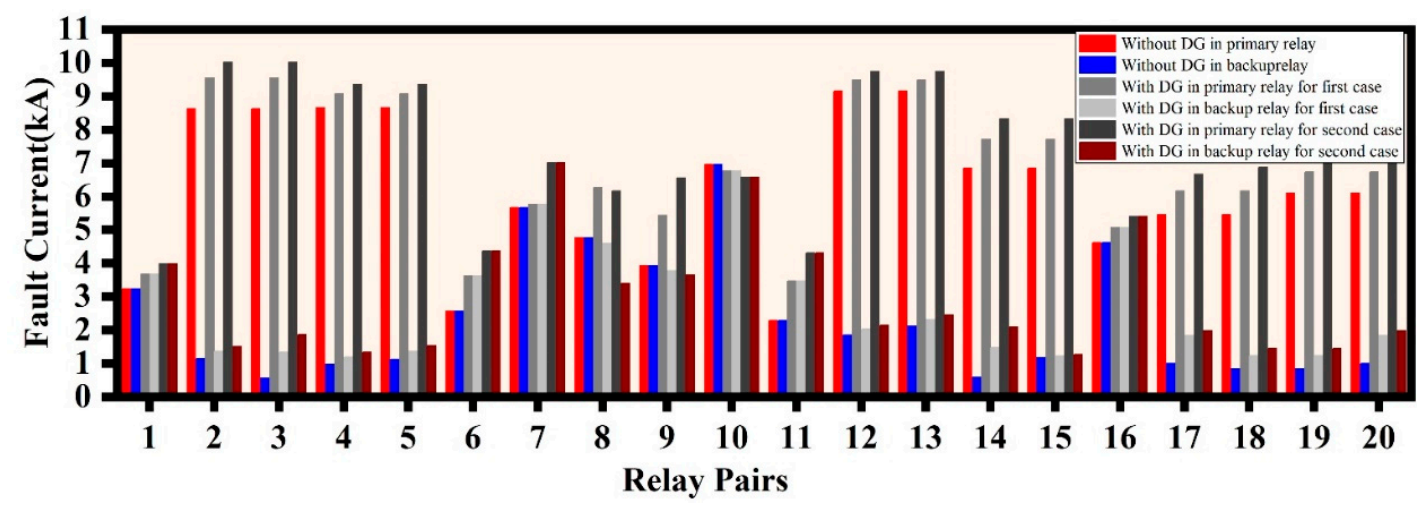

Figure 11. Fault currents in primary and backup relays without distributed generation (DG) and with (DG) for both cases. 
Table 4. Relay settings obtained with particle swarm optimization (PSO)-LP and HHO-LP for IEEE-8 bus system at a wind speed of $10 \mathrm{~m} / \mathrm{s}$. TMS, time multiplier setting.

\begin{tabular}{ccccccc}
\hline \multirow{2}{*}{ Relay } & \multicolumn{2}{c}{ Conventional } & \multicolumn{2}{c}{ PSO-LP [55] } & \multicolumn{2}{c}{ HHO-LP } \\
\cline { 2 - 7 } & TMS & $\mathbf{I}_{\mathbf{p}} \mathbf{( k A )}$ & TMS & $\mathbf{I}_{\mathbf{p}} \mathbf{( k A )}$ & TMS & $\mathbf{I}_{\mathbf{p}} \mathbf{( k A )}$ \\
\hline 1 & 0.7 & 0.114 & 0.6 & 0.124 & 0.471 & 0.156 \\
2 & 0.8 & 0.249 & 0.806 & 0.249 & 0.685 & 0.249 \\
3 & 0.724 & 0.187 & 0.729 & 0.187 & 0.597 & 0.187 \\
4 & 0.7 & 0.213 & 0.648 & 0.21 & 0.464 & 0.27 \\
5 & 0.7 & 0.142 & 0.6 & 0.142 & 0.399 & 0.193 \\
6 & 0.743 & 0.171 & 0.677 & 0.171 & 0.592 & 0.171 \\
7 & 0.7 & 0.155 & 0.6 & 0.155 & 0.448 & 0.211 \\
8 & 0.8 & 0.164 & 0.827 & 0.164 & 0.815 & 0.163 \\
9 & 0.7 & 0.13 & 0.6 & 0.131 & 0.522 & 0.177 \\
10 & 0.8 & 0.12 & 0.767 & 0.12 & 0.742 & 0.121 \\
11 & 0.8 & 0.203 & 0.731 & 0.203 & 0.712 & 0.202 \\
12 & 0.8 & 0.183 & 0.913 & 0.183 & 0.894 & 0.183 \\
13 & 0.7 & 0.138 & 0.647 & 0.187 & 0.635 & 0.187 \\
14 & 0.7 & 0.183 & 0.605 & 0.249 & 0.594 & 0.249 \\
\hline
\end{tabular}

Table 5. Operation time (TOP) of primary and backup relays for all pairs of IEEE-8 bus system with conventional settings and those updated with PSO-LP and HHO-LP.

\begin{tabular}{ccccccccc}
\hline \multirow{2}{*}{ Pair } & PR & BR & \multicolumn{2}{c}{ Conventional } & \multicolumn{2}{c}{ PSO-LP [55] } & \multicolumn{2}{c}{ HHO-LP } \\
\cline { 3 - 8 } & & & TOP $_{\mathbf{P R}}$ & TOP $_{\text {BR }}$ & TOP $_{\mathbf{P R}}$ & TOP $_{\text {BR }}$ & TOP $_{\text {PR }}$ & TOP $_{\text {BR }}$ \\
\hline 1 & 1 & 6 & 1.362 & 1.643 & 1.197 & 1.497 & 1.010 & 1.309 \\
2 & 8 & 7 & 1.322 & 2.199 & 1.367 & 1.885 & 1.345 & 1.645 \\
3 & 8 & 9 & 1.322 & 2.051 & 1.367 & 1.764 & 1.345 & 1.768 \\
4 & 2 & 1 & 1.502 & 2.036 & 1.513 & 1.812 & 1.286 & 1.586 \\
5 & 2 & 7 & 1.502 & 2.203 & 1.513 & 1.888 & 1.286 & 1.648 \\
6 & 9 & 10 & 1.424 & 1.588 & 1.223 & 1.522 & 1.174 & 1.476 \\
7 & 3 & 2 & 1.427 & 1.725 & 1.437 & 1.738 & 1.177 & 1.477 \\
8 & 10 & 11 & 1.360 & 1.738 & 1.304 & 1.588 & 1.264 & 1.544 \\
9 & 4 & 3 & 1.463 & 1.636 & 1.348 & 1.647 & 1.049 & 1.349 \\
10 & 11 & 12 & 1.541 & 1.495 & 1.408 & 1.706 & 1.369 & 1.671 \\
11 & 5 & 4 & 1.484 & 1.707 & 1.272 & 1.572 & 0.939 & 1.240 \\
12 & 12 & 13 & 1.362 & 1.774 & 1.555 & 1.855 & 1.523 & 1.820 \\
13 & 12 & 14 & 1.362 & 1.881 & 1.555 & 1.856 & 1.523 & 1.822 \\
14 & 6 & 5 & 1.314 & 2.043 & 1.197 & 1.751 & 1.047 & 1.344 \\
15 & 6 & 14 & 1.314 & 2.512 & 1.197 & 2.595 & 1.047 & 2.548 \\
16 & 13 & 8 & 1.310 & 1.577 & 1.326 & 1.628 & 1.302 & 1.602 \\
17 & 7 & 5 & 1.281 & 1.860 & 1.098 & 1.594 & 0.897 & 1.207 \\
18 & 7 & 13 & 1.281 & 2.174 & 1.098 & 2.338 & 0.897 & 2.295 \\
19 & 14 & 1 & 1.310 & 1.997 & 1.242 & 1.776 & 1.220 & 1.551 \\
20 & 14 & 9 & 1.310 & 1.796 & 1.242 & 1.544 & 1.220 & 1.520 \\
\hline
\end{tabular}




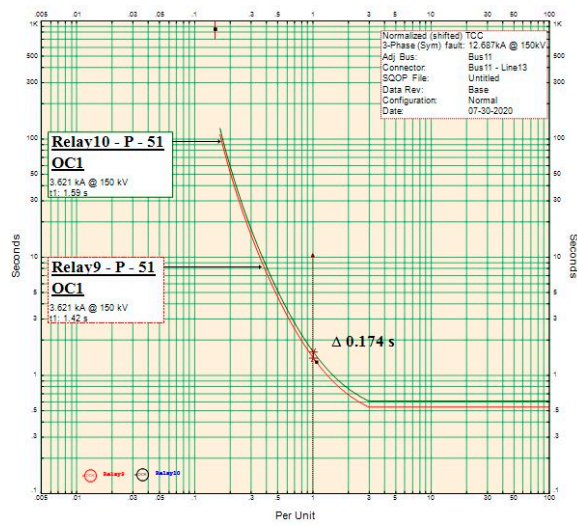

(a)

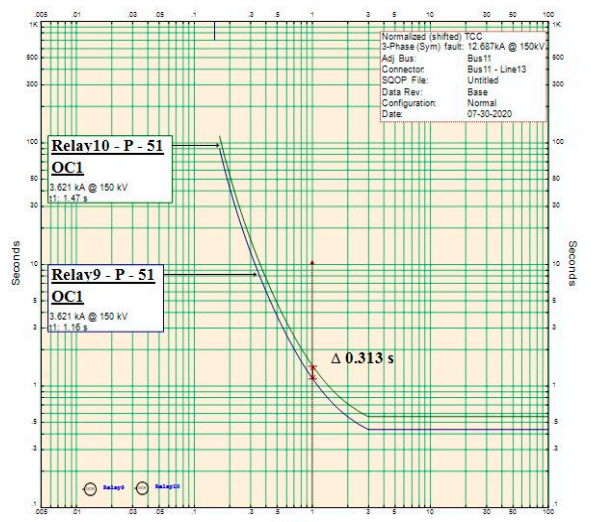

(b)

Figure 12. Primary and backup relay pair characteristics for relay pair 6 (a) with conventional settings, and (b) with settings updated using the proposed algorithm.

In the first case, with the conventional relay settings, the total operation time of primary and backup relays was $28.716 \mathrm{~s}$ and $43.541 \mathrm{~s}$, respectively. With the relay settings obtained using PSO-LP [55], the overall operation time for the same primary and backup relays was $26.470 \mathrm{~s}$ and $35.568 \mathrm{~s}$, respectively. Lastly, the time achieved upon optimizing the relay settings with the proposed HHO-LP was $23.93 \mathrm{~s}$ and $32.434 \mathrm{~s}$, respectively, which is much lower than that obtained using the conventional and PSO-LP methods. In the second case, with a $20 \mathrm{~m} / \mathrm{s}$ wind speed, HHO-LP reduced the total operation time of primary-backup relays by $19.86 \%$ compared to conventional settings and by $11.522 \%$ compared to PSO-LP. No miscoordination was reported with HHO-LP in all 20 relay pairs. The optimal relay settings and relay operating time for the second case are shown in Figures 13 and 14, respectively. The CTI between primary and backup relay pairs with conventional settings and those obtained using PSO-LP [55] and HHO-LP for both cases is reflected in Figure 15. It can be seen that, with the proposed approach, the CTI of 0.3 was maintained in all relay pairs, and the results were satisfactory. The proposed algorithm was also verified by changing the location and size of WTGs, and it is shown in Table 6 that the proposed HHO-LP worked well in all conditions. The overall performance in terms of an improvement in the reduction of time in all cases is given in Table 7.

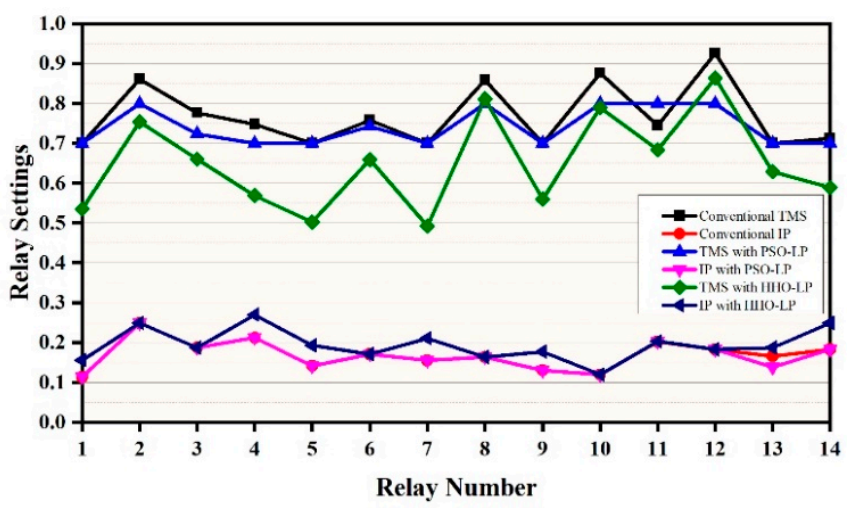

Figure 13. Relay settings for the IEEE-8 bus system. 


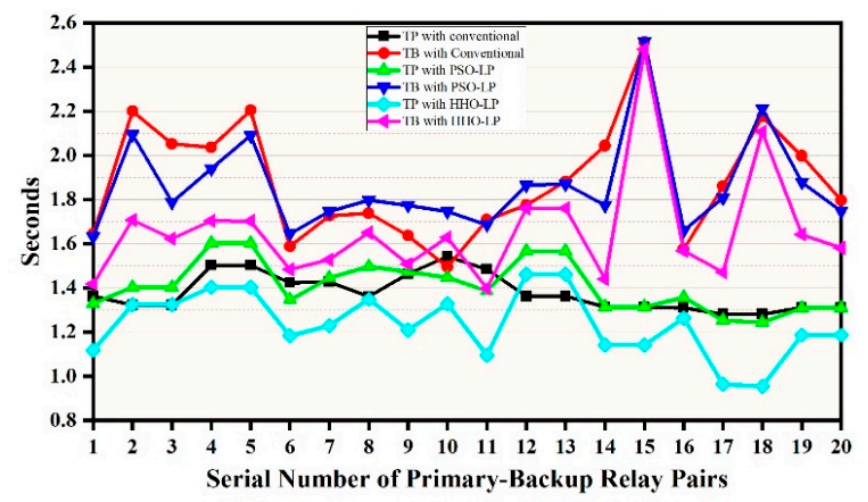

Figure 14. Primary and backup relay pairs as a function of operation time with a wind speed of $20 \mathrm{~m} / \mathrm{s}$ and an angle variation of $10^{\circ}$ using conventional settings and those updated with PSO-LP and HHO-LP.

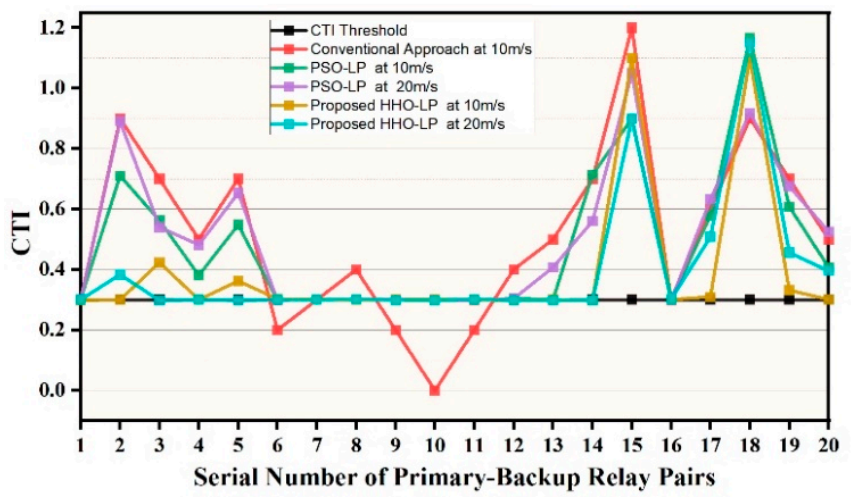

Figure 15. CTI obtained with conventional settings and those updated with PSO-LP and HHO-LP for IEEE-8 bus system for all cases.

Table 6. Primary and backup relay operation times with variable wind turbine generator (WTG) capacity and location.

\begin{tabular}{ccccc}
\hline \multirow{2}{*}{ WTG Size and Location } & \multicolumn{2}{c}{ PSO-LP [55] } & \multicolumn{2}{c}{ HHO-LP } \\
\cline { 2 - 5 } & TOP $_{\mathbf{P R}}$ & TOP $_{\mathbf{B R}}$ & TOP PR $_{\mathbf{P R}}$ & TOP $_{\mathbf{B R}}$ \\
\hline 20 WTGs of 1.5 MVA each at bus 3 & $17.17 \mathrm{~s}$ & $23.85 \mathrm{~s}$ & $15.88 \mathrm{~s}$ & $21.36 \mathrm{~s}$ \\
15 WTGs of 2.5 MVA each at bus 4 & $15.25 \mathrm{~s}$ & $22.44 \mathrm{~s}$ & $13.44 \mathrm{~s}$ & $19.57 \mathrm{~s}$ \\
20 WTGs at bus 3 and 10 WTGs at bus 4 each of 1.5 MVA & $28.17 \mathrm{~s}$ & $37.27 \mathrm{~s}$ & $24.73 \mathrm{~s}$ & $33.16 \mathrm{~s}$ \\
15 WTGs at bus 3 and 10 WTGs at bus 6 each of 1.5 MVA & $26.47 \mathrm{~s}$ & $35.57 \mathrm{~s}$ & $23.93 \mathrm{~s}$ & $32.43 \mathrm{~s}$ \\
\hline
\end{tabular}

Table 7. Performance improvement in terms of overall operation time of relay obtained using proposed HHO-LP.

\begin{tabular}{|c|c|c|c|c|c|c|}
\hline \multicolumn{2}{|c|}{ WTG Integration } & \multirow{2}{*}{$\begin{array}{c}\text { Conventional Settings } \\
\text { Operation Time (s) } \\
\sum\left(t_{p}+t_{b}\right)\end{array}$} & \multicolumn{2}{|c|}{ PSO-LP [55] } & \multicolumn{2}{|c|}{ Proposed Approach HHO-LP } \\
\hline Bus No. & Size (MW) & & $\begin{array}{l}\text { Operation Time (s) } \\
\qquad \sum\left(t_{p}+t_{b}\right)\end{array}$ & $\begin{array}{c}\text { Time Reduction } \\
(\%)\end{array}$ & $\begin{array}{c}\text { Operation Time (s) } \\
\sum \sum\left(t_{p}+t_{b}\right)\end{array}$ & Time Reduction (\%) \\
\hline 3 & 30 & 52.14 & 41.02 & 21.327 & 37.24 & 28.577 \\
\hline 4 & 37.5 & 48.76 & 37.69 & 22.703 & 33.01 & 32.301 \\
\hline 3,6 & 60,30 & 72.28 & 62.038 & 14.169 & 56.36 & 22.026 \\
\hline 3,4 & 30,15 & 76.06 & 65.44 & 13.963 & 57.89 & 23.889 \\
\hline 3,6 & $22.5,15$ & 75.44 & 62.04 & 17.623 & 56.36 & 25.292 \\
\hline
\end{tabular}

\subsubsection{Jhimpir Wind-Farm-Integrated Substation}

The Jhimpir power substation is a typical wind-farm-integrated substation in the Jamshoro city of Sindh province in Pakistan [56]. The geographical coordinates of this location are latitude $=24.4769$ and longitude $=67.9240$, and the hub height is $80 \mathrm{~m}$. This wind farm consists of 31 wind turbine generators, 
each of capacity 1.6 MW. A doubly fed induction type generator (GE 1.6 MW/103) is installed in the WF. The cut-in, cut-out, and rated wind speed are $3.5 \mathrm{~m} / \mathrm{s}, 25 \mathrm{~m} / \mathrm{s}$, and $12 \mathrm{~m} / \mathrm{s}$, respectively. The generated voltage is $0.690 \mathrm{kV}$, which is stepped up to $22 \mathrm{kV}$. Then, the $22 \mathrm{kV}$ lines are connected to $132 \mathrm{kV}$ lines with a step-up transformer of $22 \mathrm{kV} / 132 \mathrm{kV}, 100 \mathrm{MVA}$. A one-line diagram of the wind-farm-integrated substation is given in Figure 16. This system has 36 overcurrent relays and there are 35 primary-backup relays pairs, as given in Table 8 . The predicted and measured wind speeds for one day in all four seasons are already reflected in Figure 7. It can be seen that wind speed is high during the spring season; thus, it can have a high impact on the variation in fault current level. Therefore, to validate the proposed algorithm in the Jhimpir wind-farm-integrated substation, one hour was selected from the day of the spring season, i.e., 10:00 a.m. to 11:00 a.m. on 15 July of 2019.

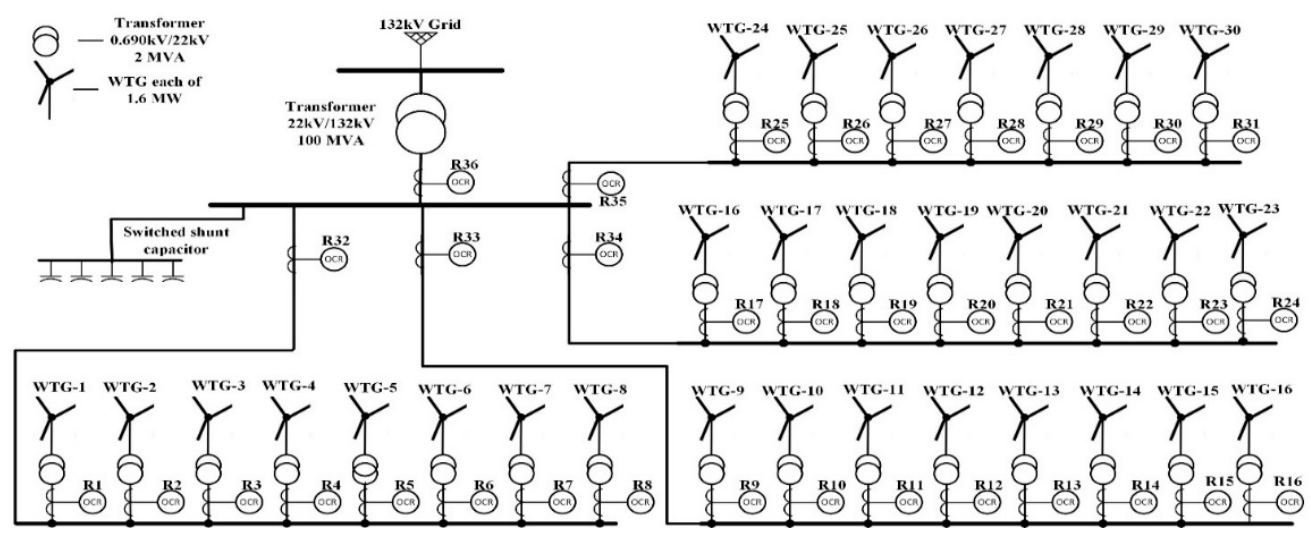

Figure 16. One-line diagram of the Jhimpir wind-farm-integrated substation.

Table 8. Primary-backup relay pairs for the Jhimpir wind-farm-integrated substation.

\begin{tabular}{|c|c|c|c|c|c|c|c|c|c|c|c|c|c|c|c|}
\hline Pair & PR & BR1 & BR2 & Pair & PR & BR1 & BR2 & Pair & PR & BR1 & BR2 & Pair & PR & BR1 & BR2 \\
\hline 1 & R1 & R32 & R36 & 10 & R10 & R33 & R36 & 19 & R19 & R34 & R36 & 28 & R28 & R35 & R36 \\
\hline 2 & $\mathrm{R} 2$ & R32 & R36 & 11 & R11 & R33 & R36 & 20 & R20 & R34 & R36 & 29 & R29 & R35 & R36 \\
\hline 3 & R3 & R32 & R36 & 12 & R12 & R33 & R36 & 21 & R21 & $\mathrm{R} 34$ & R36 & 30 & R30 & R35 & R36 \\
\hline 4 & $\mathrm{R} 4$ & R32 & R36 & 13 & R13 & R33 & R36 & 22 & R22 & R34 & R36 & 31 & R31 & R35 & R36 \\
\hline 5 & R5 & $\mathrm{R} 32$ & R36 & 14 & R14 & R33 & R36 & 23 & $\mathrm{R} 23$ & R34 & R36 & 32 & R32 & R36 & - \\
\hline 6 & R6 & R32 & R36 & 15 & R15 & R33 & R36 & 24 & R24 & R35 & R36 & 33 & R33 & R36 & - \\
\hline 7 & R7 & R32 & R36 & 16 & R16 & R33 & R36 & 25 & R25 & R35 & R36 & 34 & R34 & R36 & - \\
\hline 8 & R8 & R32 & R36 & 17 & R17 & R34 & R36 & 26 & R26 & R35 & R36 & 35 & R35 & R36 & - \\
\hline 9 & R9 & R33 & R36 & 18 & R18 & R34 & R36 & 27 & $\mathrm{R} 27$ & R35 & R36 & & & & \\
\hline
\end{tabular}

The minimum and maximum limits of TMS were 0.5 and 1.1, whereas, for $\mathrm{I}_{\mathrm{p}}$, these limits were $1.1 \times \mathrm{I}_{\text {Load }}$ and $1.5 \times \mathrm{I}_{\text {Load }}$ respectively. The CTI, in this case was set to 0.3 . The proposed algorithm was implemented, and the relay settings were updated after every $5 \mathrm{~min}$. The TMS and $\mathrm{I}_{\mathrm{p}}$ for all relays using PSO-LP and HHO-LP updated at each interval are given in Table 9. The operation time of primary-backup relay pairs and the CTI for the 12 intervals of one hour are reflected in Figure 17. The results show that the proposed algorithm reduced the overall operation time of relays and also maintained the CTI between primary-backup relay pairs, which ensured the reliability and security of the power system. The overall performance in terms of an improvement in the reduction of time in all cases is given in Table 10. The computation time was reduced in the proposed algorithm because the relay settings were determined earlier on the basis of the predicted fault current level. If the difference between the predicted and actual fault current due to wind-speed variation was greater than $2 \%$, the actual values were then updated, and the HHO-LP algorithm was implemented during the current interval to optimize the relay settings on the basis of the actual FCL. 
Table 9. Relay settings for 12 intervals of one hour from 10:00 a.m.-11:00 a.m. on 15 July 2019 obtained using PSO-LP and the proposed HHO-LP.

\begin{tabular}{|c|c|c|c|c|c|c|c|c|c|c|c|c|c|c|c|c|c|c|c|c|c|c|c|c|}
\hline \multirow[b]{3}{*}{ Pair } & \multicolumn{4}{|c|}{ 10:00 a.m. } & \multicolumn{4}{|c|}{ 10:05 a.m. } & \multicolumn{4}{|c|}{ 10:10 a.m. } & \multicolumn{4}{|c|}{ 10:15 a.m. } & \multicolumn{4}{|c|}{ 10:20 a.m. } & \multicolumn{4}{|c|}{ 10:25 a.m. } \\
\hline & \multicolumn{2}{|c|}{ PSO-LP } & \multicolumn{2}{|c|}{ HHO-LP } & \multicolumn{2}{|c|}{ PSO-LP } & \multicolumn{2}{|c|}{ HHO-LP } & \multicolumn{2}{|c|}{ PSO-LP } & \multicolumn{2}{|c|}{ HHO-LP } & \multicolumn{2}{|c|}{ PSO-LP } & \multicolumn{2}{|c|}{ HHO-LP } & \multicolumn{2}{|c|}{ PSO-LP } & \multicolumn{2}{|c|}{ HHO-LP } & PSO- & $-L P$ & $\mathrm{HHO}$ & -LP \\
\hline & TMS & $I_{p}$ & TMS & $I_{p}$ & TMS & $I_{p}$ & TMS & $I_{p}$ & TMS & $I_{p}$ & TMS & $I_{p}$ & TMS & $I_{p}$ & TMS & $I_{p}$ & TMS & $\mathbf{I}_{\mathbf{P}}$ & TMS & $\mathbf{I}_{\mathbf{P}}$ & TMS & $\mathbf{I}_{\mathbf{P}}$ & TMS & $I_{p}$ \\
\hline 1 & 0.17 & 0.38 & 0.11 & 0.47 & 0.11 & 0.23 & 0.14 & 0.15 & 13 & 0.49 & 0.14 & 0.54 & 0.15 & 0.11 & 0.14 & 0.36 & 0.13 & 0.40 & 0.11 & 0.39 & 0.16 & 0.41 & 0.12 & 0.34 \\
\hline 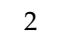 & 0.16 & 0.21 & 0.13 & 0.39 & & 0.17 & 12 & 0.39 & & 0.36 & 12 & & 11 & 0.23 & 0.11 & & 11 & 0.23 & 0.14 & 0.42 & 18 & 0.18 & .12 & 0.24 \\
\hline 3 & & 0.50 & 11 & & & 0.33 & & & & 0.13 & & & & & 0.11 & & & 0.38 & 14 & 12 & & 38 & 10 & 22 \\
\hline 4 & 0.13 & 0.30 & 0.13 & 0.13 & 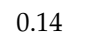 & 0.40 & & 0. & & 0.55 & & & 11 & & 0.11 & & 0.12 & 0.44 & 11 & & 14 & 19 & 11 & 12 \\
\hline 5 & 0.13 & 0.36 & 0.11 & 0.12 & 0.13 & 0.52 & 012 & 0.23 & & 0.51 & 12 & 0.57 & 11 & 0.48 & 0.11 & & 0.17 & 0.52 & 0.14 & 0.36 & 13 & 0.41 & .12 & 0.29 \\
\hline 6 & & 0.42 & & & & 0.18 & & & & 0.24 & & & & & 0.12 & & & & 14 & & & 52 & 13 & 22 \\
\hline 7 & 0.14 & 0.40 & 0.10 & 0.20 & & 0.22 & & 0. & & 0.18 & & & 16 & & 0.12 & & 12 & 0.24 & 13 & 6 & 12 & 37 & 12 & 31 \\
\hline 8 & 0.17 & 0.36 & 0.11 & 0.18 & 017 & 0.42 & & 0.26 & & 0.50 & 012 & & & & 0.14 & & & & 0.10 & 0.13 & 14 & 0.18 & 0.12 & 0.26 \\
\hline 9 & & 0.32 & & & & 0.5 & & & & & & & & & 4 & & & & & & & 34 & 11 & 34 \\
\hline 10 & 0.12 & 0. & & 0. & & 0.2 & & 0.2 & & 0.16 & & & & & 0.11 & & 18 & 0. & 11 & & 15 & 19 & 14 & 18 \\
\hline 11 & 0.13 & 0.54 & 0.12 & 0.3 & & 0.32 & & 0.36 & & 0.27 & & & & & 0.12 & & & & 11 & & & 0.54 & .13 & 0.19 \\
\hline 12 & & & & & & & & & & & & & & & & & & & & & & & & \\
\hline 13 & & 0.21 & & 0.2 & & 0.1 & & 0.2 & & 0.5 & & & & & & & & & & & & & 12 & \\
\hline 14 & & 0.34 & 013 & 0.44 & & 0.1 & & 0.1 & & 0.32 & & & & & & & & & & & & 18 & 12 & 42 \\
\hline 15 & & 0. & & 0. & & 0.2 & & & & & & & & & & & & & & & & & 12 & 38 \\
\hline 16 & 0.1 & 0.20 & & 0.3 & & 0.5 & & 0.1 & & 0. & & & & & 0. & & & & 0.10 & 4 & 15 & & 12 & 0.12 \\
\hline 17 & 0.12 & 0.30 & 011 & 0.5 & & 0.27 & & 0.18 & & 0.27 & & & & & 0.12 & & & & 12 & & 14 & 0.14 & 13 & 41 \\
\hline 18 & & & & 0. & & & & & & & & & & & & & & & & & & & 11 & 14 \\
\hline 19 & 0.14 & 0.55 & 0.1 & 0.2 & & 0.3 & & 0. & & 0.2 & & & & & 0 & & & & 0.10 & & 14 & 53 & .14 & 0.33 \\
\hline 20 & 0.14 & 0.22 & 012 & 0.3 & & 0.5 & & 0.3 & & 0.30 & & & & & 0.12 & & & & 12 & & 15 & 0.27 & .13 & 0.30 \\
\hline 2 & & & & & & 0.3 & & & & & & & & & & & & & & & & & & \\
\hline 22 & & 0.46 & & 0. & & 0.3 & & 0. & & & & & & & & & & & & & 18 & 4 & 10 & 38 \\
\hline 23 & & & & & & & & & & 0.2 & & & & & & & & & & & & & & \\
\hline & & & & & & & & & & & & & & & & & & & & & & & 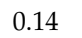 & \\
\hline 25 & & 0.2 & & 0. & & 0. & & & & & & & & & & & & & & & & 17 & 12 & 25 \\
\hline 26 & & & & 0.2 & & 0.3 & & & & & & & & & & & & & & & & & 12 & 30 \\
\hline 27 & & & & & & & & & & & & & & & & & & & & & & & & \\
\hline 28 & & 0. & & 0. & & 0. & & 0. & & & & & & & & & & & & & & 0.28 & .10 & 39 \\
\hline 29 & & 0.40 & & 0. & & 0.4 & & 0.3 & & 0.5 & 0. & & & & & & & 0. & & & .14 & 0.33 & 0.11 & 0.33 \\
\hline & & & & & & & & & & & & & & & & & & & & & & & & \\
\hline 31 & & & & & & 0. & & 0 . & & & & & & & & & & 0.22 & & & 17 & & 0.12 & 0.20 \\
\hline 32 & 0.23 & 0.43 & 0.19 & 0.4 & & 0.2 & 0. & 0.2 & & 0.1 & 0. & & & 0. & 0. & 0.2 & & 0.64 & 25 & 0.25 & 29 & 0.25 & 0.18 & 0.36 \\
\hline 33 & & & & & & & & & & & & & & & & & & & & & & & & \\
\hline 34 & & & & & & 0. & & 0. & & 0. & & & & & & & & 0.67 & 0.10 & 0.46 & .34 & 0.21 & 0.23 & 0.29 \\
\hline 35 & 0.30 & 0.26 & 0.25 & 0.4 & 0.21 & 0.5 & 0.2 & 0.38 & 0.2 & 0.34 & 0.1 & 0. & 0. & 0.50 & 0.1 & 0. & 0.21 & 0.52 & 0.19 & 0.44 & 0.27 & 0.30 & 0.24 & 0.22 \\
\hline 36 & 0.23 & 0.43 & 0.17 & 0.15 & 0.19 & 0.53 & 0.24 & 0.28 & 0.27 & 0.29 & 0.21 & 0.36 & 0.29 & 0.19 & 0.13 & 0.55 & 0.21 & 0.47 & 0.33 & 0.12 & 0.21 & 0.27 & 0.15 & 0.35 \\
\hline
\end{tabular}


Table 9. Cont

\begin{tabular}{|c|c|c|c|c|c|c|c|c|c|c|c|c|c|c|c|c|c|c|c|c|c|c|c|c|}
\hline \multirow{3}{*}{ Pair } & \multicolumn{4}{|c|}{ 10:30 a.m. } & \multicolumn{4}{|c|}{ 10:35 a.m. } & \multicolumn{4}{|c|}{ 10:40 a.m. } & \multicolumn{4}{|c|}{ 10:454 a.m. } & \multicolumn{4}{|c|}{ 10:50 a.m. } & \multicolumn{4}{|c|}{ 10:55 a.m. } \\
\hline & \multicolumn{2}{|c|}{ PSO-LP } & \multicolumn{2}{|c|}{ HHO-LP } & \multicolumn{2}{|c|}{ PSO-LP } & \multicolumn{2}{|c|}{ HHO-LP } & \multicolumn{2}{|c|}{ PSO-LP } & \multicolumn{2}{|c|}{ HHO-LP } & \multicolumn{2}{|c|}{ PSO-LP } & \multicolumn{2}{|c|}{ HHO-LP } & \multicolumn{2}{|c|}{ PSO-LP } & \multicolumn{2}{|c|}{ HHO-LP } & PSO & -LP & HHO & D-LP \\
\hline & TMS & $I_{p}$ & MS & $I_{p}$ & TMS & $I_{p}$ & IS & $I_{p}$ & TMS & $I_{p}$ & MS & $\mathbf{I}_{\mathfrak{p}}$ & TMS & $I_{p}$ & AS & $\mathbf{I}_{\mathbf{p}}$ & MS & $\mathbf{I}_{\mathbf{P}}$ & AS & $I_{P}$ & MS & $\mathbf{I}_{\mathbf{P}}$ & MS & $I_{p}$ \\
\hline 1 & 0.11 & 28 & & & & & & & & & & & & & 11 & 18 & & 32 & 13 & 0.29 & 15 & 47 & 10 & 0.31 \\
\hline 2 & & & & & & & & & & & & & & & & & & & & & & & & \\
\hline 3 & & & & & & & & & & & & & & & & & & & & & & & & \\
\hline 4 & & & & 0 & & & & & & & & & & & & & & & & & & & & \\
\hline 5 & 0.14 & & & & & & & & & & & & & & & & & & & & & & & 24 \\
\hline 6 & & & & & & & & & & & & & & & & & & & & & & & & 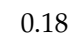 \\
\hline 7 & & & & & & & & & & & & & & & & & & & & & & & & \\
\hline 8 & & & & & & & & & & & & & & & & & & & & & & & & \\
\hline 9 & & & & & & & & & & & & & & & & & & & & & & & & \\
\hline 10 & & & & & & & & & & & & & & & & & & & & & & & & \\
\hline 11 & & & & & & & & & & & & & & & & & & & & & & & & \\
\hline 12 & & & & & & & & & & & & & & & & & & & & & & & & \\
\hline 13 & & & & & & & & & & & & & & & & & & & & & & & & \\
\hline 14 & & & & & & & & & & & & & & & & & & & & & & & & \\
\hline- & & & & & & & & & & & & & & & & & & & & & & & & \\
\hline 16 & & & & & & & & & & & & & & & & & & & & & & & & \\
\hline 17 & & & & & & & & & & & & & & & & & & & & & & & & \\
\hline 18 & & & & & & & & & & & & & & & & & & & & & & & & 0.16 \\
\hline ما & & & & & & & & & & & & & & & & & & & & & & & & \\
\hline- & & & & & & & & & & & & & & & & & & & & & & & & \\
\hline 21 & & & & & & & & & & & & & & & & & & & & & & & & 41 \\
\hline 22 & & & & & & & & & & & & & & & & & & & & & & & & 0.42 \\
\hline 23 & & & & & & & & & & & & & & & & & & & & & & & & \\
\hline 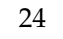 & & & & & & & & & & & & & & & & & & & & & & & & \\
\hline 25 & & & & & & & & & & & & & & & & & & & & & & & & \\
\hline 26 & & & & & & & & & & & & & & & & & & & & & & 26 & & 0.18 \\
\hline & & & & & & & & & & & & & & & & & & & & & & & & \\
\hline 2 & & & & & & & & & & & & & & & & & & & & & & & & \\
\hline 2 & & & & & & & & & & & & & & & & & & & & & & & & 0.23 \\
\hline 30 & & & & & & & & & & & & & & & & & & & & & 19 & 19 & 13 & 0.16 \\
\hline 31 & & & & & & & & & & & & & & & & & & & & & & & & \\
\hline & & & & & & & & & & & & & & & & & & & & & & & & \\
\hline 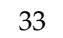 & & & & & & & & & & & & & & & & & & & & & & & & \\
\hline 34 & & 0. & & 0.2 & & & & & & & & & & & & & & & & & 25 & 65 & 0.30 & 0.22 \\
\hline 35 & & 0. & & 0.4 & & & & 0. & & 0. & & & & & & & & & & & 0.20 & 0.58 & .24 & 0.32 \\
\hline 36 & 0.18 & 0.54 & & o & 0.17 & 0.37 & & 0.25 & 0.21 & 0.28 & 0.17 & 0.34 & 0.32 & 0.33 & 0.37 & 0.17 & 0.34 & 0.32 & 0.3 & 0.24 & 0.43 & 0.15 & 0.22 & 0.42 \\
\hline
\end{tabular}


Primary Relay Time with PSO-LP $\longrightarrow$ Backup Relay Time with PSO-LP $\longrightarrow$ CTI with PSO-LP Primary Relay Time with HHO-LP $—$ Backup Relay Time with HHO-LP $— C T I$ with HHO-LP

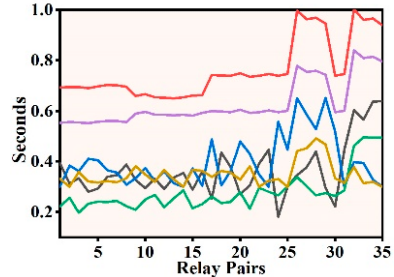

(a)

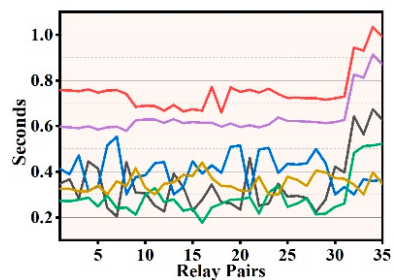

(c)

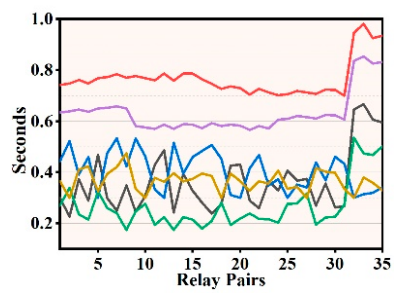

(e)

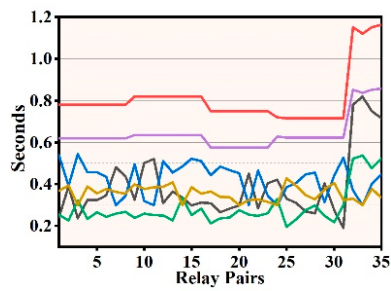

(g)

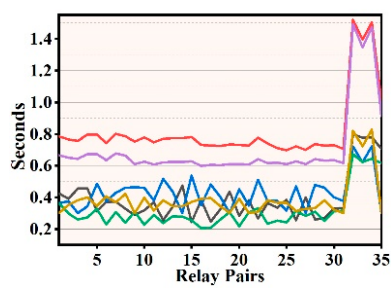

(i)

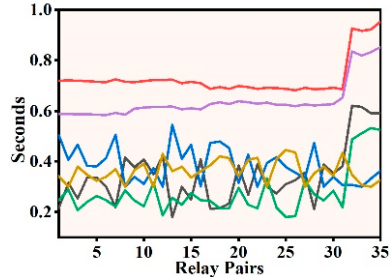

(b)

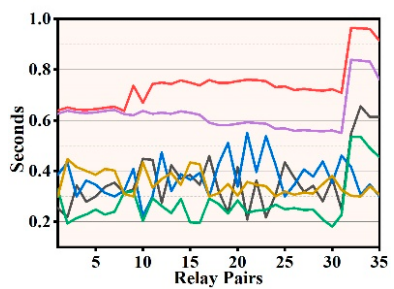

(d)

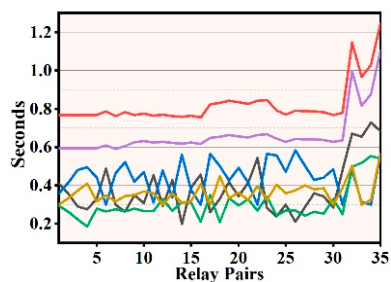

(f)

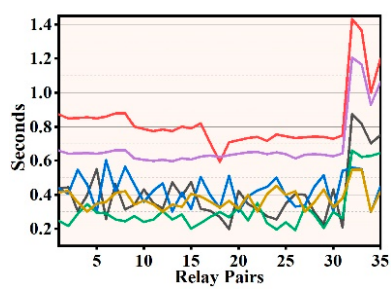

(h)

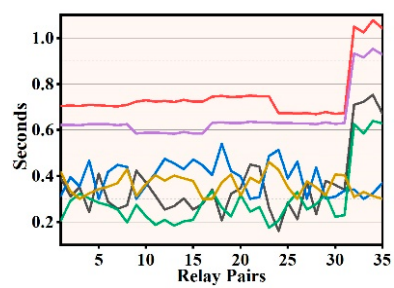

(j)

Figure 17. Cont. 


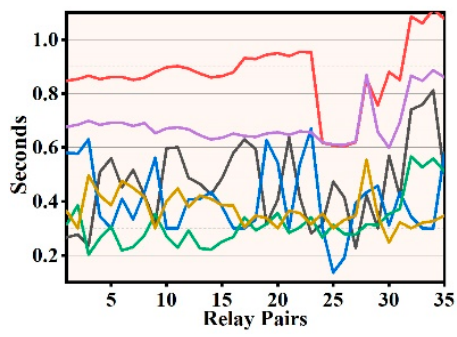

$(\mathbf{k})$

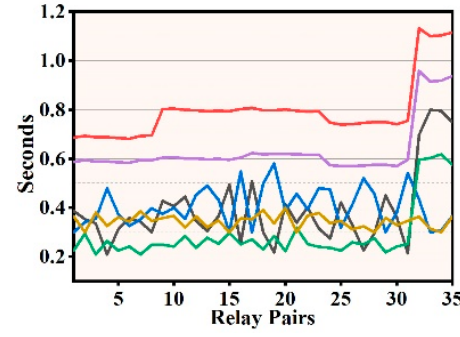

(1)

Figure 17. Operation time of primary-backup relays for all relay pairs on 15 July 2019 at (a) 10:00 a.m., (b) 10:05 a.m., (c) 10:10 a.m., (d) 10:15 a.m., (e) 10:20 a.m., (f) 10:25 a.m., (g) 10:30 a.m., (h) 10:35 am, (i) 10:40 a.m., (j) 10:454 a.m., (k) 10:50 a.m., and (1) 10:55 a.m.

Table 10. Performance improvement in terms of the overall operation time of relays obtained using the proposed HHO-LP.

\begin{tabular}{|c|c|c|c|c|c|}
\hline \multirow{2}{*}{ Interval } & \multirow{2}{*}{$\begin{array}{c}\text { Conventional Settings } \\
\text { Operation Time (s) } \\
\sum\left(t_{p}+t_{b}\right)\end{array}$} & \multicolumn{2}{|c|}{ PSO-LP [55] } & \multicolumn{2}{|c|}{ Proposed Approach HHO-LP } \\
\hline & & $\begin{array}{l}\text { Operation Time (s) } \\
\sum\left(t_{p}+t_{b}\right)\end{array}$ & $\begin{array}{c}\text { Time } \\
\text { Reduction (\%) }\end{array}$ & $\begin{array}{l}\text { Operation Time (s) } \\
\sum \sum\left(t_{p}+t_{b}\right)\end{array}$ & $\begin{array}{c}\text { Time } \\
\text { Reduction (\%) }\end{array}$ \\
\hline 1 & 51.248 & 39.515 & 22.894 & 31.860 & 37.831 \\
\hline 2 & 48.066 & 37.643 & 21.684 & 32.078 & 33.262 \\
\hline 3 & 49.125 & 38.540 & 21.547 & 32.457 & 33.93 \\
\hline 4 & 50.864 & 38.632 & 24.048 & 31.638 & 37.799 \\
\hline 5 & 51.660 & 39.521 & 23.497 & 31.445 & 39.131 \\
\hline 6 & 53.981 & 42.180 & 21.861 & 33.891 & 37.217 \\
\hline 7 & 52.112 & 41.919 & 19.559 & 32.514 & 37.607 \\
\hline 8 & 55.561 & 43.171 & 22.299 & 34.741 & 37.472 \\
\hline 9 & 53.046 & 42.348 & 20.167 & 35.726 & 32.651 \\
\hline 10 & 49.220 & 38.790 & 21.933 & 33.189 & 32.57 \\
\hline 11 & 58.756 & 47.044 & 19.9332 & 35.210 & 40.074 \\
\hline 12 & 52.550 & 41.651 & 20.740 & 32.374 & 38.394 \\
\hline
\end{tabular}

\section{Conclusions}

The disturbance in protection coordination caused by variations in the fault current level due to wind-speed variation in a wind-farm-integrated power system was investigated in this paper. The proposed algorithm consists of two steps. In the first step, the wind speed is predicted by forecasting it with hybrid ANFIS-SARIMA for a time interval of five minutes, and the fault current level is calculated in advance. Then, to reduce the overall operating times of relays in the second step, the hybrid HHO-LP is proposed for optimal relay coordination by optimizing the relay settings on the basis of the predicted fault current level. These optimal settings are transferred to relays at the start of each interval. If the difference between the actual and predicted value is more than $2 \%$, then the HHO-LP is again run during the interval, and the relay settings are updated, which is a very rare case. The proposed algorithm was tested on a modified IEEE-8 bus system with WTGs and a local wind-farm-integrated substation. The results show that the proposed algorithm provided the optimal relay settings following the variation in fault current level due to wind-speed variation. No miscoordination was seen, and the proper CTI was maintained in all primary-backup relay pairs in all cases for both test benches with a considerable reduction in the overall operation time of relays, which shows the effectiveness of the proposed algorithm.

Author Contributions: Conceptualization, M.R. and L.H.; methodology, M.R. and L.H.; software, M.R. and L.H.; validation, M.R., L.H., M.S. (Muhammad Shafiq), and M.W.; formal analysis, M.R. and L.H.; investigation, M.R., L.H., and M.W.; resources, M.R., L.H., and M.S. (Mohamed Sharaf); data curation, S.A., M.W., M.S. (Mohamed Sharaf), and M.S. (Muhammad Shafiq); writing_original draft preparation, M.R.; writing_review and editing, M.R., M.S. (Muhammad Shafiq), and S.A.; visualization, M.R., S.A., and M.S. (Muhammad Shafiq); supervision, L.H.; project administration, L.H.; funding acquisition, L.H., M.S. (Muhammad Shafiq), and M.S. (Mohamed Sharaf). All authors have read and agreed to the published version of the manuscript. 
Funding: This research is funded by the Deanship of Scientific Research at King Saud University through research group No (RG- 1438-089) and in part by the National Natural Science Foundation of China (NNSFC) through grant number 51707034. The authors also thank the Electrical Engineering Department, Southeast University and Lucheng Hong for the support given in conducting the research.

Conflicts of Interest: The authors declare no conflict of interest.

\section{Appendix A}

Table A1. WTG parameters used in IEEE-8 bus system.

\begin{tabular}{|c|c|c|c|c|}
\hline Parameters & WF-1 & WF-2 & Parameters & WF-1 \\
\hline Number of machines & 20 & 10 & Rated wind speed & $13 \mathrm{~m} / \mathrm{s}$ \\
\hline Nominal power of each machine & \multicolumn{2}{|c|}{$3 \mathrm{MW}$} & $\mathrm{L}_{\mathrm{S}}$ & $0.0397 \mathrm{pu}$ \\
\hline Generating voltage & \multicolumn{2}{|c|}{$0.690 \mathrm{kV}$} & $\mathrm{L}_{\mathrm{r}}$ & $0.0397 \mathrm{pu}$ \\
\hline Frequency & \multicolumn{2}{|c|}{$50 \mathrm{~Hz}$} & $\mathrm{~L}_{\mathrm{m}}$ & $1.354 \mathrm{pu}$ \\
\hline
\end{tabular}

\section{References}

1. Guo, X.; Yang, X. The Development of Wind Power under the Low-Carbon Constraints of Thermal Power in the Beijing-Tianjin-Hebei Region. IEEE Access 2020, 8, 44783-44797. [CrossRef]

2. Zhou, X.; Wang, Z.; Ma, Y.; Gao, Z. An overview on development of wind power generation. In Proceedings of the 2018 IEEE International Conference on Mechatronics and Automation (ICMA), Changchun, China, 5-8 August 2018; pp. 2042-2046. [CrossRef]

3. Spear, S. Wind Energy Could Generate Nearly 20 Percent of World's Electricity by 2030. 2014. Available online: https://www.ecowatch.com/wind-energy-could-generate-nearly-20-percent-of-worlds-electricityby--1881962962.html (accessed on 15 July 2020).

4. Dupont, E.; Koppelaar, R.; Jeanmart, H. Global available wind energy with physical and energy return on investment constraints. Appl. Energy 2018, 209, 322-338. [CrossRef]

5. Dehghanpour, E.; Karegar, H.K.; Kheirollahi, R.; Soleymani, T. Optimal coordination of directional overcurrent relays in microgrids by using cuckoo-linear optimization algorithm and fault current limiter. IEEE Trans. Smart Grid 2018, 9, 1365-1375. [CrossRef]

6. Purwar, E.; Vishwakarma, D.N.; Singh, S.P. A Novel Constraints Reduction-Based Optimal Relay Coordination Method Considering Variable Operational Status of Distribution System with DGs. IEEE Trans. Smart Grid 2019, 10, 889-898. [CrossRef]

7. Shamsoddini, M.; Vahidi, B.; Razani, R.; Mohamed, Y.A.R.I. A novel protection scheme for low voltage DC microgrid using inductance estimation. Int. J. Electr. Power Energy Syst. 2020, 120, 105992. [CrossRef]

8. Farzinfar, M.; Jazaeri, M. A novel methodology in optimal setting of directional fault current limiter and protection of the MG. Int. J. Electr. Power Energy Syst. 2020, 116, 105564. [CrossRef]

9. Gashteroodkhani, O.A.; Majidi, M.; Etezadi-Amoli, M. A combined deep belief network and time-time transform based intelligent protection Scheme for microgrids. Electr. Power Syst. Res. 2020, 182, 106239. [CrossRef]

10. El-Naily, N.; Saad, S.M.; Hussein, T.; Mohamed, F.A. A novel constraint and non-standard characteristics for optimal over-current relays coordination to enhance microgrid protection scheme. IET Gener. Transm. Distrib. 2019, 13, 780-793. [CrossRef]

11. Purwar, E.; Singh, S.P.; Vishwakarma, D.N. A Robust Protection Scheme Based on Hybrid Pick-Up and Optimal Hierarchy Selection of Relays in the Variable DGs-Distribution System. IEEE Trans. Power Deliv. 2020, 35, 150-159. [CrossRef]

12. Lwin, M.; Guo, J.; Dimitrov, N.B.; Santoso, S. Stochastic Optimization for Discrete Overcurrent Relay Tripping Characteristics and Coordination. IEEE Trans. Smart Grid 2019, 10, 732-740. [CrossRef]

13. Dubey, R.K.; Samantaray, S.R.; Panigrahi, B.K. Adaptive distance relaying scheme for transmission network connecting wind farms. Electr. Power Compon. Syst. 2014, 42, 1181-1193. [CrossRef]

14. Ikegami, T.; Urabe, C.T.; Saitou, T.; Ogimoto, K. Numerical definitions of wind power output fluctuations for power system operations. Renew. Energy 2018, 115, 6-15. [CrossRef] 
15. Abdelaziz, A.Y.; Talaat, H.E.A.; Nosseir, A.I.; Hajjar, A.A. An adaptive protection scheme for optimal coordination of overcurrent relays. Electr. Power Syst. Res. 2002, 61, 1-9. [CrossRef]

16. Rizwan, M.; Hong, L.; Waseem, M.; Shu, W. Sustainable protection coordination in presence of distributed generation with distributed network. Int Trans Electr Energ Syst. 2019, e12217. [CrossRef]

17. Laway, H.O.; Gupta, A.N. Integrated software for optimal directional overcurrent relay coordination. Electr. Mach. Power Syst. 1994, 22, 125-136. [CrossRef]

18. Damborg, M.J.; Ramaswami, R.; Venkata, S.S. Group Puget. Computer aided transmission protection system design. IEEE Trans. Power Appar. Syst. 1984, PAS-103, 51-59. [CrossRef]

19. Sharifian, H.; Abyaneh, H.A.; Salman, S.K.; Mohammadi, R.; Razavi, F. Determination of the minimum break point set using expert system and genetic algorithm. IEEE Trans. Power Deliv. 2010, 25, 1284-1295. [CrossRef]

20. Ezzeddine, M.; Kaczmarek, R.; Iftikhar, M.U. Coordination of directional overcurrent relays using a novel method to select their settings. IET Gener. Transm. Distrib. 2011, 5, 743-750. [CrossRef]

21. Razavi, F.; Abyaneh, H.A.; Al-Dabbagh, M.; Mohammadi, R.; Torkaman, H. A new comprehensive genetic algorithm method for optimal overcurrent relays coordination. Electr. Power Syst. Res. 2008, 78, 713-720. [CrossRef]

22. Chattopadhyay, B. An online relay coordination algorithm for adaptive protection using linear programming technique. IEEE Power Eng. Rev. 1996, 16, 47-48.

23. Urdaneta, A.J. Coordination of directional overcurrent relay timing using linear programming. IEEE Power Eng. Rev. 1996, 16, 44-45. [CrossRef]

24. Roy, S.; Babu, P.S.; Babu, N.V.P. Intelligent Overcurrent and Distance Relays Coordination: A Comparative Analysis using GA, PSO and TLBO. In Proceedings of the 2018 4th International Conference on Electrical Energy Systems (ICEES), Chennai, India, 7-9 February 2018; pp. 162-167. [CrossRef]

25. Zeineldin, H.H.; El-Saadany, E.F.; Salama, M.M.A. Optimal coordination of overcurrent relays using a modified particle swarm optimization. Electr. Power Syst. Res. 2006, 76, 988-995. [CrossRef]

26. Amraee, T. Coordination of Directional Overcurrent. IEEE Trans. Power Deliv. 2012, 27, 1415-1422. [CrossRef]

27. Bedekar, P.P.; Bhide, S.R. Optimum coordination of overcurrent relay timing using continuous genetic algorithm. Expert Syst. Appl. 2011, 38, 11286-11292. [CrossRef]

28. Orazgaliyev, D.; Tleubayev, A.; Zholdaskhan, B.; Nunna, H.S.V.S.K.; Dadlani, A.; Doolla, S. Adaptive Coordination Mechanism of Overcurrent Relays using Evolutionary Optimization Algorithms for Distribution Systems with DGs. In Proceedings of the 2019 International Conference on Smart Energy Systems and Technologies (SEST), IPorto, Portugal, 9-11 September 2019; pp. 1-6. [CrossRef]

29. Singh, M.; Panigrahi, B.K.; Abhyankar, A.R. Optimal coordination of directional over-current relays using Teaching Learning-Based Optimization (TLBO) algorithm. Int. J. Electr. Power Energy Syst. 2013, 50, $33-41$. [CrossRef]

30. Tripathi, J.M.; Adhishree, S.; Krishan, R. Optimal coordination of overcurrent relays using gravitational search algorithm with DG penetration. In Proceedings of the 2014 6th IEEE Power India International Conference (PIICON), Delhi, India, 5-7 December 2014; pp. 1-6. [CrossRef]

31. Saha, D.; Datta, A.; Das, P. Optimal coordination of directional overcurrent relays in power systems using symbiotic organism search optimisation technique. IET Gener. Transm. Distrib. 2016, 10, 2681-2688. [CrossRef]

32. ARivas, E.L.; Pareja, L.A.G.; Abrão, T. Coordination of distance and directional overcurrent relays using an extended continuous domain ACO algorithm and an hybrid ACO algorithm. Electr. Power Syst. Res. 2019, 170, 259-272. [CrossRef]

33. Moradi, M.H.; Abedinie, M. A combination of genetic algorithm and particle swarm optimization for optimal DG location and sizing in distribution systems. In Proceedings of the 2010 th Internation Power Energy Conference IPEC, Singapore, 27-29 October 2010; pp. 858-862. [CrossRef]

34. Sanjay, R.; Jayabarathi, T.; Raghunathan, T.; Ramesh, V.; Mithulananthan, N. Optimal allocation of distributed generation using hybrid grey Wolf optimizer. IEEE Access 2017, 5, 14807-14818. [CrossRef]

35. Darabi, A.; Bagheri, M.; Gharehpetian, G.B. Electrical Power and Energy Systems metaheuristic approaches for exact overcurrent relay coordination. Int. J. Electr. Power Energy Syst. 2020, 114, 105420. [CrossRef]

36. Srinivas, S.T.P.; Swarup, K.S. Optimal Relay Coordination for Microgrids Using Hybrid Modified Particle Swarm Optimization-Interval Linear Programming Approach. In Proceedings of the 2017 North American Power Symposium (NAPS), Morgantown, WV, USA, 17-19 September 2017. 
37. Kale, V.S.; Agarwal, M.; Kesarkar, P.D.; Regmi, D.R.; Chaudhary, A.; Killawala, C. Optimal coordination of overcurrent relays using genetic algorithm and simulated annealing. In Proceedings of the 2014 International Conference on Control, Instrumentation, Energy and Communication (CIEC), Calcutta, India, 31 January-2 February 2014; pp. 361-365. [CrossRef]

38. Al-Roomi, A.R.; El-Hawary, M.E. Optimal coordination of double primary directional overcurrent relays using a new combinational bbo/de algorithm. Can. J. Electr. Comput. Eng. 2019, 42, 135-147. [CrossRef]

39. Noghabi, A.S.; Sadeh, J.; Mashhadi, H.R. Considering different network topologies in optimal overcurrent relay coordination using a hybrid GA. IEEE Trans. Power Deliv. 2009, 24, 1857-1863. [CrossRef]

40. Wagner, R.; Antoniou, I.; Pedersen, S.M.; Courtney, M.S.; Jørgensen, H.E. The influence of the wind speed profile on wind turbine performance measurements. Wind Energy 2009, 12, 348-362. [CrossRef]

41. Kuo, C.; Lin, W.S.; Dressel, C.a.; Chiu, A.W.L. Ensemble Empirical Mode Decomposition. Source 2011, 55, 6281-6284.

42. Geurts, M.; Box, G.E.P.; Jenkins, G.M. Time Series Analysis: Forecasting and Control. J. Mark. Res. 1977, 14, 269. [CrossRef]

43. Zhang, J.; Wei, Y.M.; Tan, Z.F.; Wang, K.; Tian, W. A hybrid method for short-term wind speed forecasting. Sustainability 2017, 9, 596. [CrossRef]

44. Khosravi, A.; Koury, R.N.N.; Machado, L.; Pabon, J.J.G. Prediction of wind speed and wind direction using artificial neural network, support vector regression and adaptive neuro-fuzzy inference system. Sustain. Energy Technol. Assess. 2018, 25, 146-160. [CrossRef]

45. Reynolds, O.; April, R., IV. On the dynamical theory of incompressible viscous fluids and the determination of the criterion. Philos. Trans. R. Soc. Lond. 1895, 186, 123-164. [CrossRef]

46. Choukulkar, A.; Pichugina, Y.; Clack, C.T.M.; Calhoun, R.; Banta, R.; Brewer, A.; Hardesty, M. A new formulation for rotor equivalent wind speed for wind resource assessment and wind power forecasting. Wind Energy 2016, 19, 1439-1452. [CrossRef]

47. Baskut, O.; Ozgener, O.; Ozgener, L. Effects of meteorological variables on exergetic efficiency of wind turbine power plants. Renew. Sustain. Energy Rev. 2010, 14, 3237-3241. [CrossRef]

48. Ojaghi, M.; Mohammadi, M. Unified modeling technique for axially uniform and nonuniform eccentricity faults in three-phase squirrel cage induction motors. IEEE Trans. Ind. Electr. 2018, 65, 5292-5301. [CrossRef]

49. Heidari, A.A.; Mirjalili, S.; Faris, H.; Aljarah, I.; Mafarja, M.; Chen, H. Harris hawks optimization: Algorithm and applications. Futur. Gener. Comput. Syst. 2019, 97, 849-872. [CrossRef]

50. Zhou, J.; Shi, J.; Li, G. Fine tuning support vector machines for short-term wind speed forecasting. Energy Convers. Manag. 2011, 52, 1990-1998. [CrossRef]

51. Nguyen, L.; Metzger, M. Comparison of forecasting methods for vertical axis wind turbine applications in an urban/suburban area. J. Renew. Sustain. Energy 2017, 9. [CrossRef]

52. Hong, Y.Y.; Rioflorido, C.L.P.P. A hybrid deep learning-based neural network for $24-\mathrm{h}$ ahead wind power forecasting. Appl. Energy 2019, 250, 530-539. [CrossRef]

53. Luo, X.; Sun, J.; Wang, L.; Wang, W.; Zhao, W.; Wu, J.; Wang, J.-H.; Zhang, Z. Short-term wind speed forecasting via stacked extreme learning machine with generalized correntropy. IEEE Trans. Ind. Inform. 2018, 14, 4963-4971. [CrossRef]

54. Chabanloo, R.M.; Abyaneh, H.A.; Kamangar, S.S.H.; Razavi, F. Optimal combined overcurrent and distance relays coordination incorporating intelligent overcurrent relays characteristic selection. IEEE Trans. Power Deliv. 2011, 26, 1381-1391. [CrossRef]

55. Papaspiliotopoulos, V.A.; Kurashvili, T.A.; Korres, G.N. Optimal coordination of directional overcurrent relays in distribution systems with distributed generation based on a hybrid PSO-LP algorithm. IET Conf. Publ. 2014, 2014, 1-6. [CrossRef]

56. Pakistan's Alternative Energy Development Board. Available online: http://www.aedb.org/ (accessed on 15 July 2020).

(C) 2020 by the authors. Licensee MDPI, Basel, Switzerland. This article is an open access article distributed under the terms and conditions of the Creative Commons Attribution (CC BY) license (http://creativecommons.org/licenses/by/4.0/). 